\title{
The zone of influence: matching sea level variability from coastal altimetry and tide gauges for vertical land motion estimation
}

\author{
Julius Oelsmann, Marcello Passaro, Denise Dettmering, Christian Schwatke, Laura Sánchez, and Florian Seitz \\ Deutsches Geodätisches Forschungsinstitut der Technischen Universität München, Arcisstraße 21, 80333 Munich, Germany
}

Correspondence: Julius Oelsmann (julius.oelsmann@tum.de)

Received: 22 April 2020 - Discussion started: 27 May 2020

Revised: 27 August 2020 - Accepted: 26 October 2020 - Published: 12 January 2021

\begin{abstract}
Vertical land motion (VLM) at the coast is a substantial contributor to relative sea level change. In this work, we present a refined method for its determination, which is based on the combination of absolute satellite altimetry (SAT) sea level measurements and relative sea level changes recorded by tide gauges (TGs). These measurements complement VLM estimates from the GNSS (Global Navigation Satellite System) by increasing their spatial coverage. Trend estimates from the SAT and TG combination are particularly sensitive to the quality and resolution of applied altimetry data as well as to the coupling procedure of altimetry and TGs. Hence, a multi-mission, dedicated coastal along-track altimetry dataset is coupled with high-frequency TG measurements at 58 stations. To improve the coupling procedure, a so-called "zone of influence" (ZOI) is defined, which confines coherent zones of sea level variability on the basis of relative levels of comparability between TG and altimetry observations. Selecting $20 \%$ of the most representative absolute sea level observations in a $300 \mathrm{~km}$ radius around the TGs results in the best VLM estimates in terms of accuracy and uncertainty. At this threshold, VLM SAT-TG estimates have median formal uncertainties of $0.58 \mathrm{~mm} \mathrm{yr}^{-1}$. Validation against GNSS VLM estimates yields a root mean square $\left(\mathrm{rms}_{\triangle \mathrm{VLM}}\right)$ of VLM $\mathrm{VAT}_{\mathrm{SAG}}$ and $\mathrm{VLM}_{\mathrm{GNSS}}$ differences of $1.28 \mathrm{~mm} \mathrm{yr}^{-1}$, demonstrating the level of accuracy of our approach. Compared to a reference $250 \mathrm{~km}$ radius selection, the $300 \mathrm{~km}$ zone of influence improves trend accuracies by $15 \%$ and uncertainties by $35 \%$. With increasing record lengths, the spatial scales of the coherency in coastal sea level trends increase. Therefore, the relevance of the ZOI for im-

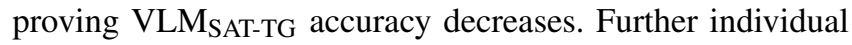
zone of influence adaptations offer the prospect of bringing the accuracy of the estimates below $1 \mathrm{~mm} \mathrm{yr}^{-1}$.
\end{abstract}

\section{Introduction}

Coastal vertical land motion (VLM) significantly contributes to relative sea level change (SLC). VLM is in many places of the same order of magnitude $\left(1-10 \mathrm{~mm} \mathrm{yr}^{-1}\right)$ as the sea level rise signal itself and displays significant spatial variations (Santamaría-Gómez et al., 2012). Consequently, VLM affects coastal impacts of climate-sensitive processes and can regionally account for large fractions of the observed and projected coastal SLC signal (Wöppelmann and Marcos, 2016; Slangen et al., 2014). Thus, the accurate estimation of VLM is vital, not only to disentangle climatic and geodynamic SLC signatures, but also to obtain more robust estimates of past and future relative SLC and its associated uncertainty (Church et al., 2013; Santamaría-Gómez et al., 2017). In this work, we present a novel approach of VLM estimation using coastal satellite altimetry, tide gauges and the Global Navigation Satellite System (GNSS).

VLM is caused by the superimposition of natural processes and anthropogenic influences in the Earth system and operates on manifold spatial and temporal scales (Pugh and Woodworth, 2014). Mechanisms such as the Glacial Isostatic Adjustment (GIA), the postglacial rebound of the Earth to changing ice and water load, cause distinct large-scale VLM, which can be assumed to be uniform on centennial timescales (Peltier, 2004). Recent acceleration of land ice mass loss was shown to additionally enhance deformation rates, posing new challenges for sea level studies due to its time-varying signal (Riva et al., 2017). Surface mass changes are also caused by terrestrial freshwater storage changes and can have smallscale effects on VLM. Groundwater pumping, for instance, contributes not only to local small-scale VLM and gravity changes, but also modifies sea level rise in distant areas (e.g., Wada et al., 2012; Veit and Conrad, 2016). Other small-scale 
VLM effects such as erosion and tectonic movements can be locally confined to several kilometers with more subtle, not necessarily linear temporal behavior (Brooks et al., 2007; Kolker et al., 2011; Poitevin et al., 2019). These and other nonlinear processes at very short timescales are particularly challenging in the estimation of a linear rate of long-term VLM from TGs, since they would appear as instabilities in the record (similarly to a change in datum).

In response to the substantial impact on relative sea level and the large spectrum of VLM sources, several strategies have been developed to estimate VLM. The ability to capture the diversity of VLM processes, however, strongly depends on the method and geodetic technique used in the VLM estimation. Furthermore, the coverage and associated accuracy of VLM estimates differ across the methods. Given that the global absolute sea level trend during the altimeter era is of the order of $3 \mathrm{~mm} \mathrm{yr}^{-1}\left(3.1 \pm 0.1 \mathrm{~mm} \mathrm{yr}^{-1}\right.$ from 1995 to 2018 as reported in Cazenave et al., 2018), one prerequisite for VLM estimation is that the associated trend uncertainty should be at least 1 order of magnitude lower than this subtle signal (Wöppelmann and Marcos, 2016). Hence, dense and accurate VLM estimates are required to complement modeled or measured rates of absolute sea level changes, which is ultimately crucial for coastal planning. Improving the reliability of VLM estimates and their associated uncertainties is thus one major concern of this study. In the following, we briefly contrast the three major approaches of deriving coastal VLM globally.

\subsection{Estimating coastal vertical land motions}

The majority of global sea level studies have utilized geodynamic GIA models to correct, for example, tide gauge records for secular land motion trends or to extrapolate future relative SLC based on climate projections (e.g., Church and White, 2011; Hay et al., 1990; Carson et al., 2016). GIA still represents the only long-term geological process for which VLM can be modeled on a global scale. However, one caveat is that GIA VLM models were shown to still be biased by imperfect assumptions of ice history and the Earth's structure (King et al., 2012), and they are thus modeldependent (Jevrejeva et al., 2014). Another foreseeable disadvantage is that the sole application of GIA models neglects other sources of VLM (e.g., tectonics, erosion and anthropogenic impacts; Wöppelmann and Marcos, 2016). This led, for instance, to discrepancies in estimated rates of historical global mean sea level (GMSL) change when comparing model-based solutions against those using measurements from GNSS (Hamlington et al., 2016).

For more than a decade, these direct geodetic estimates (GNSS, such as GPS, GLONASS and GALILEO) have been exploited to determine vertical velocities (Wöppelmann et al., 2007; Snay et al., 2007; Mazzotti et al., 2008). GNSS measurements denote the most precise source of VLM detection and are well established in local- to global-scale studies (e.g., Bouin and Wöppelmann, 2010; Fenoglio et al., 2012; Santamaría-Gómez et al., 2017). Wöppelmann and Marcos (2016) identified comparably low formal errors of GNSS VLM rates $\left(0.21 \mathrm{~mm} \mathrm{yr}^{-1}\right)$ when autocorrelation was taken into account. Santamaría-Gómez et al. (2012) estimated an accuracy of $0.6 \mathrm{~mm} \mathrm{yr}^{-1}$ of GNSS-based VLM (from at least 3 years of continuous data) by comparing 36 globally distributed colocated GNSS velocity estimates. Thus, because of its considerable accuracy, vertical GNSS velocities frequently served as benchmark estimates for many sea level applications, e.g., for GIA model evaluation or local VLM corrections of TG records (Sánchez and Bosch, 2009; Sanli and Blewitt, 2001).

For the latter use a necessary working hypothesis is that GNSS VLM represents the same movements as experienced at the tide gauge (Wöppelmann and Marcos, 2016). Because VLM is shown to potentially possess high spatial variability even on small scales (tens of kilometers), GNSS stations should ideally be very close to the tide gauge. This requirement, however, reduces the number of available colocated stations (130 GNSS stations within a $1 \mathrm{~km}$ range of GLOSS - Global Sea Level Observing System - tide gauges; Wöppelmann et al., 2019) and thus confines the global coastal coverage to mostly Europe, Japan and North America.

To extend the number of VLM estimates, several studies advanced the application of combining satellite altimetry (SAT) and tide gauge (TG) observations (Cazenave et al., 1999; Nerem and Mitchum, 2003; Kuo et al., 2004; Pfeffer and Allemand, 2016; Wöppelmann and Marcos, 2016; Kleinherenbrink et al., 2018). The principle of this approach is to subtract the absolute SLC gathered by the altimeter from relative SLC observations at the TG. Ideally, the differenced time series (SAT minus TG) yields the vertical displacement of the TG with respect to the reference of the altimeter. The accuracy of this technique is, among numerous other factors, strongly dependent on the stability of the altimeter measurement system. Major systematic errors stem from limitations in the realization of the reference frame and from limitations in the long-term stability of altimeter instruments and corrections (e.g., Couhert et al., 2015; Wöppelmann and Marcos, 2016; Watson et al., 2015). Altimetry records can be affected by globally and regionally varying drifts, which were found to be most pronounced on TOPEX altimeter side-A. The calibration of altimetry with TGs is influenced by the applied VLM correction (Watson et al., 2015). Conversely, SAT-TG VLM estimates are affected by the altimeter drift or by errors originating from the intermission drift biases (or drifts with respect to the reference mission). Due to the availability of global and continuous absolute sea level measurements, this method not only provides a complementary source to GNSS measurements, but also improves the geographical distribution of the data, as virtually every valid TG is usable.

While all three sources of information, GIA models, GNSS and "satellite altimetry minus tide gauge" (SAT-TG) techniques, have individual merits, their combined use is 
valuable to further substantiate VLM estimates. GNSS observations are necessary to validate both GIA models and the SAT-TG approach (Santamaría-Gómez et al., 2012; Wöppelmann and Marcos, 2016; Kleinherenbrink et al., 2018). Recent studies have combined all three approaches to reconstruct GMSL (Dangendorf et al., 2017) or to densify the estimation of contemporary rates of vertical land motions (Pfeffer et al., 2017) or relative sea level change (Hawkins et al., 2019). Any advancement in these individual approaches therefore supports developments of the others and improves the global assessment of coastal VLM estimates.

In this study, we focus on enhancing the application of the SAT-TG difference for VLM detection. Our investigations not only further develop the latest progress of the method, but also gain a new perspective on sea level trend and uncertainty characterization as well as quantification in coastal zones. The next section recapitulates the latest state of the VLM $_{\text {SAT-TG }}$ estimation on which we base our innovations.

\subsection{Progress in VLM estimation by satellite altimetry and tide gauge difference}

The combination of SAT and TG observations for VLM determination was steadily improved over the last 2 decades and is elaborated in the latest review by Wöppelmann and Marcos (2016), hereinafter WM16. WM16 investigated performances of different gridded and along-track altimetry products (e.g., AVISO - Archiving, Validation, and Interpretation of Satellite Oceanographic data; GSFC - Goddard Space Flight Center). They combined sea level anomalies (SLAs) as $1^{\circ}$ radius averages with monthly mean TG records from PSMSL (Permanent Service for Mean Sea Level). Among all datasets, the gridded AVISO product revealed the best correlations and residuals between altimetry and TG records. Using this dataset, WM16 also obtained the most precise VLM estimates achieved, with median formal uncertainties of $0.8 \mathrm{~mm} \mathrm{yr}^{-1}$. Validation against GNSSbased trends from ULR5 (Université de La Rochelle, Institut Géographique National analysis) at 113 colocated stations resulted in an $\mathrm{rms}_{\triangle \mathrm{VLM}}$ of $1.47 \mathrm{~mm} \mathrm{yr}^{-1}$ of VLM $\mathrm{mAT}_{\text {-TG }}$ and VLM $_{\text {GNSS }}$ trend differences, providing the highest accuracies among the datasets.

Notwithstanding the weaker performance of the alongtrack product (from GSFC) achieved in WM16, Kleinherenbrink et al. (2018) made great progress in using along-track altimetry (TOPEX, Jason-1 and Jason-2 from the Radar Altimeter Database - RADS; Scharroo et al., 2012) to estimate VLM. Their approach aimed to overcome the spatial downsampling and associated loss of information in gridded products such as AVISO. They also advanced the procedure of combining altimetry and TG data. Instead of taking $1^{\circ}$ averages around the TGs, they selected altimetry data according to different absolute correlation thresholds and implemented correlation weighting of time series. Generally, the thresholding strategy functioned as a filter to remove stations of low comparability: with varying correlations between 0.0 and 0.7 , they obtained $\mathrm{rms}_{\triangle \mathrm{VLM}}$ errors from 2.1 to $1.20 \mathrm{~mm} \mathrm{yr}^{-1}$ (at 155 stations), which significantly improved WM16's results. For a consistent set of stations, they found a slight sensitivity of the rms $\triangle \mathrm{VLM}$ to variations of the prescribed minimum correlation; however, they reported insignificant improvements of a few percent. Because they derived GNSS vertical velocities from the Nevada Geodetic Laboratory (NGL) database by taking the median of available estimates within a $50 \mathrm{~km}$ range of the TG, they increased the number at which VLM SAT-TG $_{\text {trends could be validated to }}$ 155.

Based on Kleinherenbrink et al. (2018) and WM16, we identify two essential factors which are vital for the quality of trend estimation with the SAT-TG difference. Advancements with respect to both factors not only potentially led to improved VLM estimates in Kleinherenbrink et al. (2018), but also motivate further innovations.

1. Data quality. In coastal regions the accuracy of altimetry measurements is affected by the local departure of the radar signal from the known ocean response (due to inhomogeneities of the illuminated area) and by the inaccuracy of the standard routinely applied corrections and tidal models. Developments for the solution of both issues led to rapid improvements in the recent years through, e.g., application of coastal retracking and advanced geophysical corrections (e.g., Cipollini et al., 2017; Passaro et al., 2014; Fernandes et al., 2015). Dedicated coastal altimetry datasets (e.g., COASTALT, ALES, PISTACH) might thus outperform previously applied products (e.g., AVISO), which do not yet benefit from these implementations.

2. Data selection. Next to issues concerning data quality, the second factor defining trend uncertainty is the

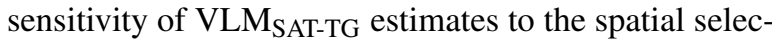
tion of altimeter data in the vicinity of the TG. WM16 showed that averaging SLA in a radius of $1^{\circ}$ around the TG resulted in higher correlations than using the bestcorrelated or the closest grid point to the TG. Kleinherenbrink et al. (2018) found a small influence of variations of absolute correlation thresholds on the trend estimates. Therefore, considering the diversity of processes which drive coastal sea level variability, such as waves, winds or coastal and bathymetric properties, an advanced adaptation of the choice of altimetry SLA might improve the representation of the signal captured by the TG.

These reasons motivate further improvements of both components: the quality of the data and the practice of combining altimetry and TG data. We aim to understand how dedicated along-track coastal altimetry can outperform standard gridded products. We also seek to generalize an optimal 
Table 1. Applied models and geophysical corrections for estimating sea level anomalies.

\begin{tabular}{lll}
\hline Parameter & Model & Reference \\
\hline $\begin{array}{l}\text { Range and sea state bias } \\
\text { Inverse barometer }\end{array}$ & ALES & (Passaro et al., 2014) \\
Wet troposphere & DAC-ERA & (Carrère et al., 2016) \\
Dry troposphere & GPD+ & (Fernandes et al., 2015) \\
Ionosphere & VMF3 & (Landskron and Böhm, 2018) \\
Ocean and load tide & NIC09 & (Scharroo and Smith, 2010) \\
Solid Earth and pole tide & IERS 2010 & (Carrère et al., 2015) \\
Mean sea surface & DTU18MSS & (Andersen et al., 2018) \\
\hline
\end{tabular}

selection of SLAs, underpinned by the local dynamical features of measured sea level variability.

In this work, we present a new approach of combining SAT and TG observations to improve VLM estimates. In contrast to previous attempts, we exploit TG and SAT data at the highest available temporal and spatial scale for globally distributed stations. We couple advanced coastal altimetry data with high-frequency TG records from the Global Extreme Sea Level Analysis (GESLA). Implementation of these high-frequency TG records constitutes a further innovation for VLM estimation. So far such data have only been applied in local studies (Idžanović et al., 2019), and monthly TG data were commonly exploited in this regard. We show that the precision and accuracy of the trend estimates can be optimized when using refined spatial selection criteria of altimetry sea level anomalies. With this approach we identify coherent zones of sea level variability that best represent the coastal in situ measurements. Our method is generally transferable to analysis of coastal sea level trend determination.

Sections 2 and 3 describe the individual datasets, applied processing steps, and the optimization of combining altimetry and TG data. Section 4 presents the performance of trend estimates, i.e., estimated uncertainties and validation against GNSS data (in this study all GNSS data are based on the Global Positioning System - GPS). Finally, we contrast our results and methods with previous work and discuss the impact of the interconnection of timescales and space scales on the evolution of coherency of sea level in coastal regions (Sect. 5).

\section{Data}

We use different altimetry products in order to assess the impact of special coastal products on associated VLM VAT-TG $_{\text {SAT }}$ trend estimates. We compare the coast-dedicated retracker ALES (Adaptive Leading Edge Subwaveform retracker; Passaro et al., 2014) along-track product against the interpolated AVISO dataset (Sects. 2.1 and 2.2). Altimetry data are combined with TG observations from the monthly mean PSMSL and the high-frequency GESLA database, which are described in Sects. 2.3 and 2.4. We develop a new coupling strategy of high-rate altimetry and TG records in Sect. 3.2.

\subsection{Coastal along-track altimetry - ALES}

The coastal altimetry product is constructed from $1 \mathrm{~Hz}$ multi-mission altimetry measurements processed by DGFITUM with OpenADB (https://openadb.dgfi.tum.de, last access: 10 December 2020). We combine data from the missions ERS-2, Envisat, Saral, Jason-1 to Jason-3 and their extended missions, which provide continuous altimetry time series of 23 years (1995-2018). For all missions, satellite orbits in ITRF2008 are used, mostly processed by CNES (GDR-E). For ERS-2, GFZ VER11 orbits are applied. The SGDR data are reprocessed with the ALES retracker (Passaro et al., 2014) and an improved sea state bias correction scheme (Passaro et al., 2018). The geophysical corrections are summarized in Table 1. They are consistent with those incorporated in the latest development of the empirical ocean tide model (EOT19p) by Piccioni et al. (2019). If available, the dynamic atmospheric correction consists of the ECMWF ERA-Interim reanalysis (DAC-ERA; Carrère et al., 2016). This product especially reduces along-track sea level errors in the earlier missions (in this study ERS-2). Because this product is unavailable for the very recent missions, we implement the DAC (Carrère and Lyard, 2003) based on ECMWF for the last cycles of Jason-2 (and its extended mission) and the full Jason-3 and Saral missions. To reduce radial errors in the different missions, the tailored coastal altimetry product is cross-calibrated using the global multi-mission crossover analysis (MMXO) (Bosch and Savcenko, 2007; Bosch et al., 2014). The MMXO minimizes a large set of globally distributed single and dual sea surface height crossover differences by least-squares adjustment. The estimated radial errors are used to correct each individual sea surface height measurement. In this way, we not only reduce orbit inconsistencies, but also those originating from the range and from applied corrections. Since we estimate a radial correction for each observation, we minimize intermission drift differences and regionally correlated errors. Note that this approach is a relative calibration and provides range bias corrections with respect to NASA/CNES reference missions. Any remaining 
absolute drift of these reference missions (with respect to TGs) still influences the drift of the whole altimeter solution.

We map all altimetry records on $1 \mathrm{~Hz}$ nominal tracks consistent with the CTOH nominal paths (Center for Topographic studies of the Ocean and Hydrosphere, http:// ctoh.legos.obs-mip.fr/, last access: 10 December 2019) of the individual missions using nearest-neighbor interpolation. Then, we scan the data for outliers along the tracks to hinder spurious extreme values from propagating in time series. This scheme features the following.

- Absolute thresholds. Any absolute SLA exceeding $2 \mathrm{~m}$ is excluded.

- Running median test. If the absolute difference of the data and its running median (centered, over 20 points) is greater than $12 \mathrm{~cm}$, data are excluded.

- Consecutive difference test. Outliers are detected when the difference of consecutive points exceeds $8 \mathrm{~cm}$. The test identifies the outliers according to the differences of the other neighboring values.

The absolute thresholds $(12,8 \mathrm{~cm})$ correspond to $2 \sigma$ of the median running variability and $2 \sigma$ of absolute consecutive differences based on the analysis of different tracks of Jason2 and ERS-2.

SLAs along the same track and cycle are then averaged over predefined areas as described in Sects. 2.5 and 2.6. We built a time series by considering all averaged SLAs from the along-track multi-mission dataset for the study period. To check for outliers in each SLA time series, we exclude values exceeding absolute values of $3 \sigma$ of the data. This cleaned $1 \mathrm{~Hz}$ coastal altimeter dataset is hereinafter called ALES and used for the combination with the TG datasets described in Sect. 3.1.

\subsection{Gridded altimetry data - AVISO}

The gridded Ssalto/Duacs altimeter product was produced and distributed by the Copernicus Marine Environment Monitoring Service (CMEMS; http://marine.copernicus.eu, last access: 10 December 2020) and is hereinafter called AVISO as it was previously distributed by CNES AVISO+. We use monthly sea level anomalies, which are resolved on a $0.25^{\circ}$ Cartesian grid and cover the period from 1992-2019. The product already includes the DAC (Carrère and Lyard, 2003), comprising the dynamical barotropic ocean response to atmospheric forcing (modeled with MOG2D-G) and the inverse barometer (IB) response. Consistent with the alongtrack dataset ALES, FES2014 (Carrère et al., 2015) is implemented to correct for tidal signals. Other corrections and preprocessing steps are documented by CMEMS.

\subsection{Monthly tide gauge data - PSMSL}

We use monthly mean TG data from the datum-controlled PSMSL (Holgate et al., 2013) database. The PSMSL consti- tutes the primary source of TG data for most sea level research and for the assessment of long-term trends of VLM based on SAT and TGs. The service undertakes quality control of the data including checks for consistency of the annual cycle, outlier detection and intercomparisons with neighboring stations, which enhances the reliability of the data. Among all available stations, we select those which contain at least 180 months (15 years) of valid measurements during the altimetric era (1993-present), resulting in a total of 627 stations. We apply the same monthly averaged DAC correction as used for the AVISO data (Carrère and Lyard, 2003). To match the DAC correction with the TG records, we select among the nine closest grid points of the solution the one which results in the highest variance reduction.

\subsection{High-frequency tide gauge data - GESLA}

In addition to monthly mean PSMSL TG data, we exploit the GESLA dataset (Woodworth et al., 2016), which contains a large global collection of high-frequency TG records with sampling rates ranging from hours down to $6 \mathrm{~min}$. The latest version, GESLA 2, contains in total 1355 station records and was assembled from a variety of international and national data banks (e.g., UHSLC - University of Hawaii Sea Level Center - and GLOSS) as well as independent sources. It thus also shares many stations with the monthly PSMSL database, the preferred dataset for VLM SAT-TG $_{\text {computation. }}$ Unfortunately, at this time, GESLA holds only data until 2015. Therefore, we also restrict the considered period for all dataset combinations (see Sect. 3.1) to before 2015. As for the PSMSL data, we select stations with at least 180 months of valid data.

In contrast to PSMSL data used in WM16, GESLA TGs feature no rigorous outlier rejection by default except that of the primary data providers (Woodworth et al., 2016). Extreme values from strong signals like tsunamis or station shifts and other irregularities are still present in the data. Some of those issues are addressed on the GESLA web page; however, for the sake of long-term trend evaluation, we perform a further global outlier analysis. Therefore, we check all TG time series manually for irregularities: station shifts from seasonal to interannual timescales are either handled by dismissing certain sections of the time series or completely excluding the TG from the analysis. Single extreme events from hourly to monthly timescales are only excluded when they deviate from the measurements by several meters because we want to maintain as much data as possible. If such events are present, we flag any values beyond the upper and lower 0.999 quantiles of a fitted normal distribution of the data. Occasionally we apply this quantile outlier exclusion recursively.

To obtain a uniform temporal resolution, we resample this outlier-free TG set to hourly records by cubic interpolation. The records are then corrected for the tidal signal and for the ocean response to atmospheric wind and pressure forc- 
ing. The tidal variability is suppressed by using a $40 \mathrm{~h}$ loess (locally estimated scatter plot smoothing) filter (Cleveland and Devlin, 1988) as in Saraceno et al. (2008). This filtering approach most effectively reduces tidal variance at periods lower than $2 \mathrm{~d}$ (e.g., reduction by more than 2 orders of magnitude at daily periods). However, tidal variability at periods larger than $2 \mathrm{~d}$ is not significantly attenuated by the filter. Therefore, one caveat of this approach is that residual tidal variance remains at longer periods between TGs and altimetry, given that the latter features a model-based adjustment for longer tides. We, however, do not apply the same tidal model to the TGs due to known issues related to decreased model performance in shallow water (Piccioni et al., 2018). In accordance with PSMSL TG data, we implement the same dynamic atmospheric correction (Carrère and Lyard, 2003). This solution features a $6 \mathrm{~h}$ sampling frequency, which is therefore downsampled to hourly anomalies by cubic interpolation. For the global dataset, we obtain a mean variance reduction of $37.8 \%$ and a mean correlation of 0.6. As in WM16 and Ponte (2006), we find a distinct latitude dependence of correlations and variance reduction, with decreasing performance nearer to the Equator. We note that the total variance reduction, which we apply to the high-rate TG data, is naturally less than in WM16, who corrected monthly mean, detrended and deseasoned data.

\section{Methods}

\subsection{Dataset combinations}

To understand the sensitivity of the VLM estimations to the (1) quality and resolution of the data and (2) the selection procedure, we analyze the performances of four different dataset combinations: ALES-PSMSL$250 \mathrm{~km}$, ALES-GESLA-250 km, AVISO-PSMSL-250 km and ALES-GESLA-ZOI.

The first three combinations are constructed to compare the performances of the along-track (ALES) against the gridded altimetry product (AVISO) combined with monthly TG observations. With ALES-GESLA-250 km we also investigate the possible advantage of using the GESLA high-rate TG product. For all these experimental sets, SLA time series are merged or averaged within a $250 \mathrm{~km}$ radius around the TGs, which is thus a selection procedure independent of the actual comparability of SLAs.

To produce the ALES-GESLA-250 km dataset, we derive differences of the merged, nonuniformly sampled SLAs and the hourly sampled GESLA TG records through cubic interpolation of the latter and a maximum allowed time lag of $3 \mathrm{~h}$ between the measurements. We downsample these high-rate differenced time series to monthly means. For ALES-PSMSL-250 km, on the other hand, we first compute monthly means from SLAs and subsequently subtract these monthly SLAs from the monthly sampled relative SLAs from PSMSL. Finally, we directly compute the differenced SAT-TG time series from the averaged monthly AVISO and the PSMSL data, which yields the AVISO-PSMSL-250 km dataset.

Using these combinations, we investigate the mere changes from differences formed using along-track data at high or at low frequency (ALES-GESLA-250 km and ALES-PSMSL-250 km) or using monthly gridded data (AVISO-PSMSL-250 km). Here, "high frequency" refers to daily timescales of variability and "low frequency" to monthly timescales. The dataset ALES-GESLA-ZOI incorporates further SLA selection schemes, which are explained in the following section.

\subsection{The zone of influence}

We aim to develop a new SLA selection scheme, which accounts for the observed coherency of sea level variability. However, due to the diversity of the underlying physical mechanisms and their complex interplay with the coast, the spatial coherency of sea level dynamics is highly variable in coastal regions (Woodworth et al., 2019). Coastally trapped waves, for instance, were argued to establish long-range correlations along the continental slopes (Hughes and Meredith, 2006) and to mediate the influence of the open ocean (Hughes et al., 2019) on the coast. While some signals, such as interannual modes of climate variability, generate high spatial coherence, other local features, such as the presence of a coastal current, can significantly modify the sea level variability within a few kilometers of the coast, as shown in the case of the seasonal signal of the Norwegian Coastal Current in Passaro et al. (2015). Accordingly, the capability to compare TG-based sea level variability with altimetry utterly depends on which timescales and length scales are resolved by the data.

The key concept of our approach is to capture the extent to which coastal altimetry measurements are similar to the in situ TG observations. To do so, we extend the methodology proposed by Santamaría-Gómez et al. (2014), who looked for the altimetry grid point most correlated with the TG, and Kleinherenbrink et al. (2018), who considered a larger set of points based on absolute thresholds of correlation. In contrast to these previous studies, we assess the influence of using relative thresholds of comparability on both the accuracy and the uncertainty of the trends.

We exploit combinations of along-track ALES data and high-frequency GESLA records to identify regions of sea level variability that show maximum coherency with TG observations, which we hereinafter call the zone of influence (ZOI). With this approach, our objective is to decrease noise of the differenced, high-frequency $\mathrm{VLM}_{\mathrm{SAT} \text {-TG }}$ time series using the ZOI to hone trends and uncertainty estimates.

To define the ZOI, we investigate different statistical criteria $S$, which provide a measure of the similarity of sea level variability between TG and SAT observations. Here, we 
use the Pearson correlation coefficient, the rms SAT-TG and the amplitude of the residual annual cycle between the TG and SAT records. We compute each of those measures for every point of the $1 \mathrm{~Hz}$ along-track data (ALES) in combination with the TG records from GESLA. As for ALES-GESLA$250 \mathrm{~km}$, TG data are interpolated onto the time step of the altimetry records. Correlations and rms SAT-TG are computed from the detrended TG and SAT time series. The amplitude of the residual annual cycle is obtained from the remaining seasonal signal of the difference of the time series (SAT-TG). We acquire a dataset containing information on the performance of multi-mission along-track data in the vicinity of every GESLA TG. The statistics are based on detrended data. Thus, all the metrics may be influenced by the similarity of the annual cycle. However, by repeating this analysis using detrended and deseasoned data (not shown), no significant differences are identified.

To define the ZOI, we select subsets of the data containing the best-performing statistics (i.e., highest correlation, lowest rms SAT-TG or residual annual cycle) above the $X$ th percentile according to the distribution of the statistic $S$ in a $300 \mathrm{~km}$ radius around the TGs. Every subset $(X, S)$ represents an individual ZOI, in which we average SLAs in accordance with the steps involved in the aforementioned $250 \mathrm{~km}$ radius selection (ALES-GESLA-250 km; Sect. 3.1). The high-rate SLA time series (ALES) are then again subtracted from GESLA, providing the ALES-GESLA-ZOI dataset for VLM estimation (Sect. 3.3).

Note that in contrast to the $250 \mathrm{~km}$ selection, we extend the range in which SLAs are taken into account to $300 \mathrm{~km}$ to define the ZOI. The previous $250 \mathrm{~km}$ selection is, as in Kleinherenbrink et al. (2018), based on the space autocorrelation scales of SLAs, which reflect characteristic eddy length scales (Stammer and Böning, 1992; Ducet et al., 2000). These scales decrease towards higher latitudes (i.e., towards the poles) with changing internal Rossby radius. However, several studies found much larger correlation length scales of SLAs, in particular along shorelines (Calafat et al., 2018; Hughes and Meredith, 2006). Mechanisms other than mesoscale eddy activity were investigated to account for these coherent changes. One example is given by Calafat et al. (2018), who analyzed the driving factors of sea level variability at the southeastern coast of the US. Using altimetry and three different ocean models, they found coherent changes in the annual amplitude of SLAs over length scales of thousands of kilometers along the coast from the Yucatán Peninsula to Cape Hatteras. While the annual cycle signal itself was dominated by steric changes, with likewise largescale correlations at the continental slope, changes in the annual amplitude were argued to be dominated by boundary waves exerted by incident Rossby waves. Because we similarly find correlations beyond the $250 \mathrm{~km}$ length scale, in particular along elongated coastal regions (Fig. 1a and b), we justify the larger $300 \mathrm{~km}$ radius.
We identify coherent zones of sea level variability represented by different selection criteria in Fig. 1. The statistics $S$ are computed based on individual along-track SLA time series (ALES) and GESLA TGs. We show different maps of these along-track statistics for (a) the Australian coast, (b) Californian coast and (c) Chichijima island (Japan). The contour in the first column exemplifies the extent of a ZOI, which represents a subset of $20 \%$ of the best-correlated data.

The obtained coherent structures reveal notable dependencies on the local bathymetric and coastal properties. Figure 1a, for instance, shows far-reaching alongshore correlations, which is supported by all of the analyzed selection criteria. In this example, the separation of the region of the coastal shelf-sea dynamics from the region of offshore variability is in good agreement with the underlying bathymetric gradients. Kurapov et al. (2016) found similarly pronounced SLA coherency along the Californian coast, as shown in Fig. 1b. Based on model data and TG observations, they explained the large-scale alongshore correlation pattern in part by the propagation of coastal trapped waves. In other locations such as Chichijima island (see Fig. 1c), coastal and bathymetric control of SL is reduced and different structures of coherency evolve. Consequently, the ZOI can strongly vary in shape depending on the local coastal features and drivers of coastal variability.

Comparing these three examples, we also observe that absolute values of the statistics differ from site to site. Correlations of along-track data near the Australian coastline, for instance, outperform the ones in the example in Fig. 1b. The same holds for rms SAT-TG values. These differences not only indicate different degrees of coherency, but can also stem from regional deviations in the quality of data, i.e., quality of TG records or error sources in the altimetric product, such as tidal adjustments or coastal corrections. Differences can also be caused by coastal properties, e.g., when the TGs are located in sheltered areas, which separates the in situ variability from the one measured at distant altimeter tracks. We therefore analyze the use of relative thresholds to select the SLAs, since setting absolute thresholds as in Kleinherenbrink et al. (2018) might not be applicable in all cases. Figure 1c also shows that different statistics can determine different extents of the ZOI, considering that rather poorly correlated areas are partially characterized by low residual annual cycle amplitudes.

A correct choice of the ZOI based on a subset of highperformance SLAs can significantly reduce the SAT-TG residuals as exemplified in Fig. 2. Here, we show three time series of SAT-TG differences for the Australian site (see Fig. 1a). The first series (Fig. 2a) indicates much lower residual noise when the time series is constructed from the $20 \%$ best SLAs (according to the rmsSAT-TG). Here, the ALES-GESLA-ZOI residuals outperform those of the other combinations (ALES-PSMSL-250 km and AVISO-PSMSL- 
(a)
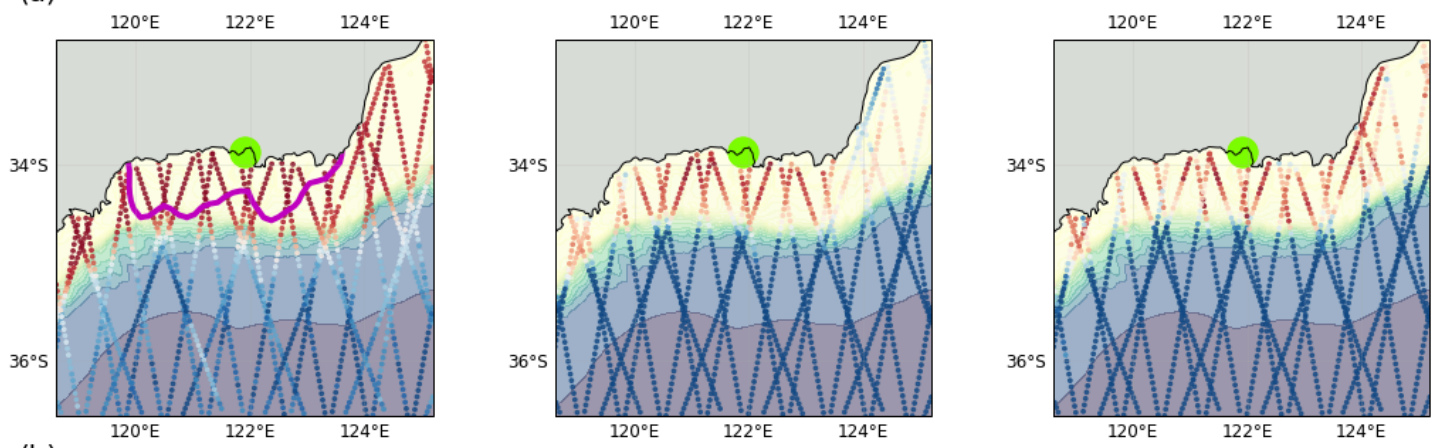

(b)
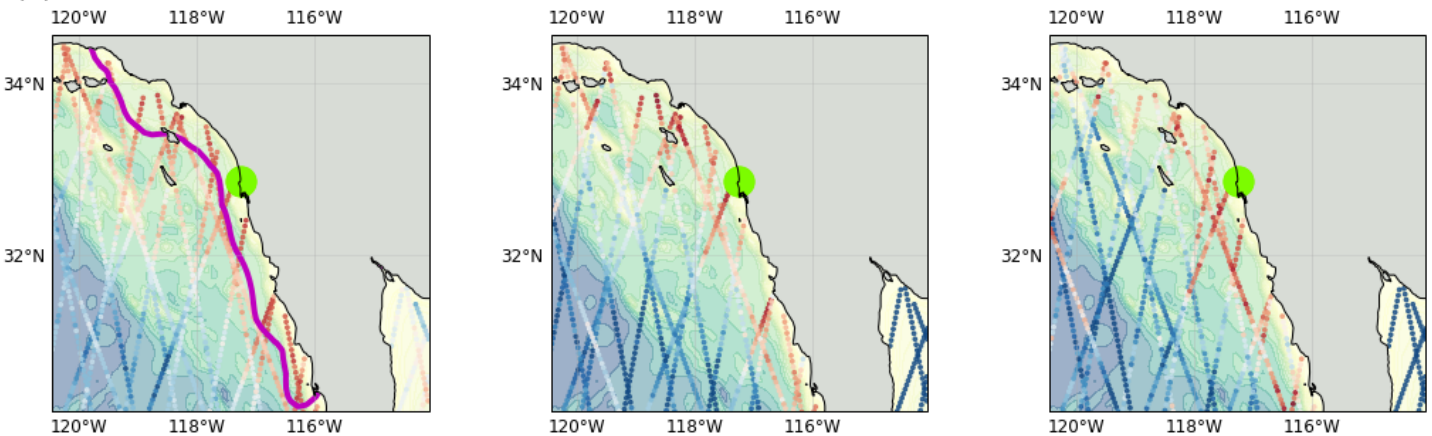

(c)
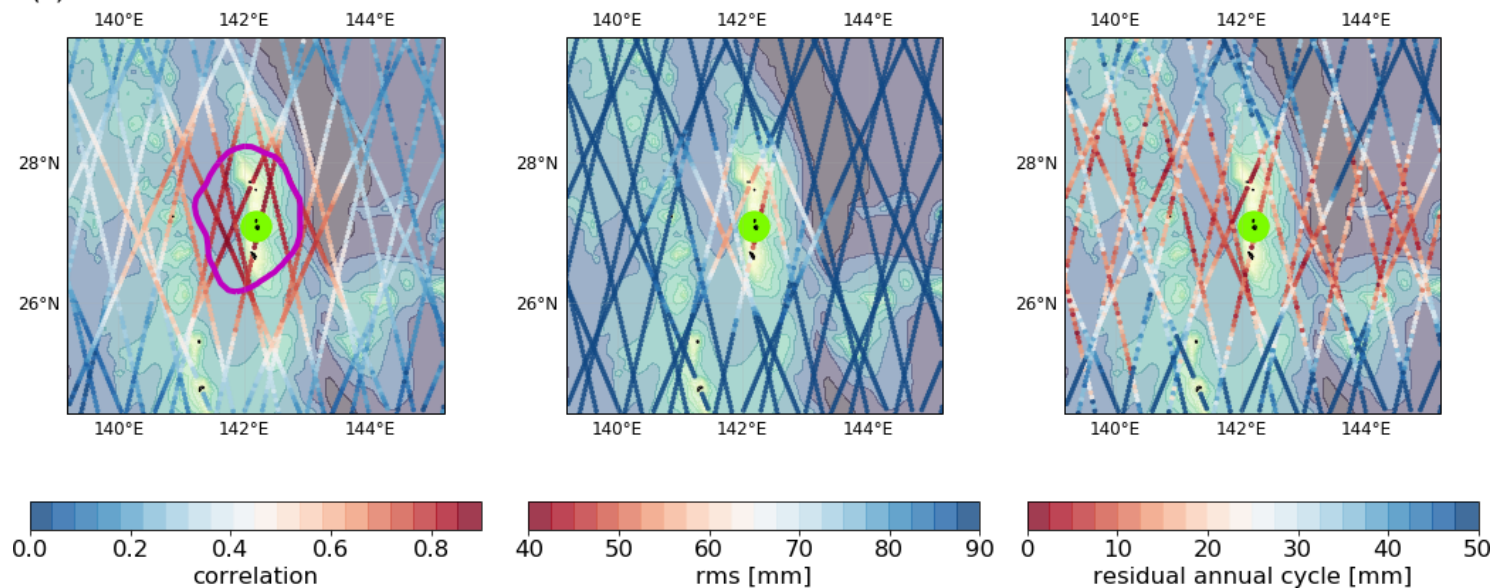

Figure 1. Zone of influence: different coherent zones of sea level variability are identified by different statistical criteria $S$. The columns show correlations, rms SAT-TG and the residual annual cycle from left to right. The metrics are computed on every point of the $1 \mathrm{~Hz}$ alongtrack product, comparing the performance of altimetry measurements with the TGs, highlighted in green (center). (a) The southern coast of Western Australia, (b) the western coast of North America (TG in San Diego) and (c) Chichijima island (Japan). The "color" contour in the first column indicates a zone of influence built from $20 \%$ of the best-correlated SLAs within a $300 \mathrm{~km}$ radius. The underlying contours denote the underlying bathymetry.

$250 \mathrm{~km}$ ), which are still affected by a pronounced annual cycle not related to VLM.

While using relative thresholds can reduce the noise of

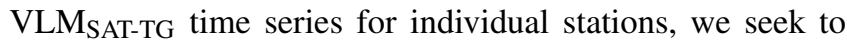
identify a globally optimal ZOI definition and associated criteria and thresholds, which lead to the largest improvements

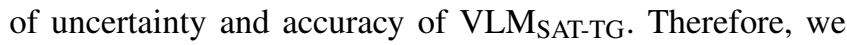
vary the relative thresholds $X$ between 0.0 and 0.975 (with a step size of 0.025 ), which refers to using $100 \%$ and $2.5 \%$ of the best-performing SLAs according to each criteria. For each threshold and criterion we derive an individual global VLM $_{\text {SAT-TG }}$ trend and uncertainty dataset. We validate the performance of the trend estimates for a specific ZOI definition in accordance with Sect. 3.4. Optimal parameters $X$ and $S$ are then suggested for the global application (Sect. 4.2). 


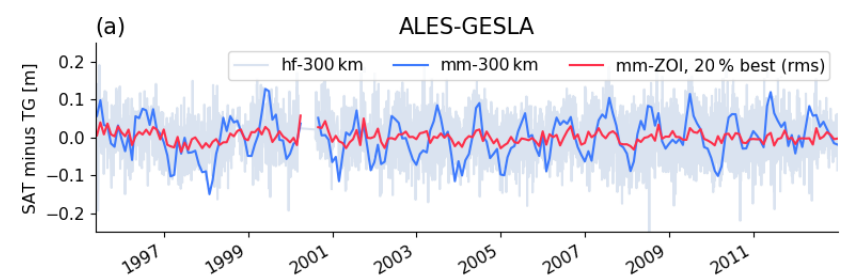

(b)
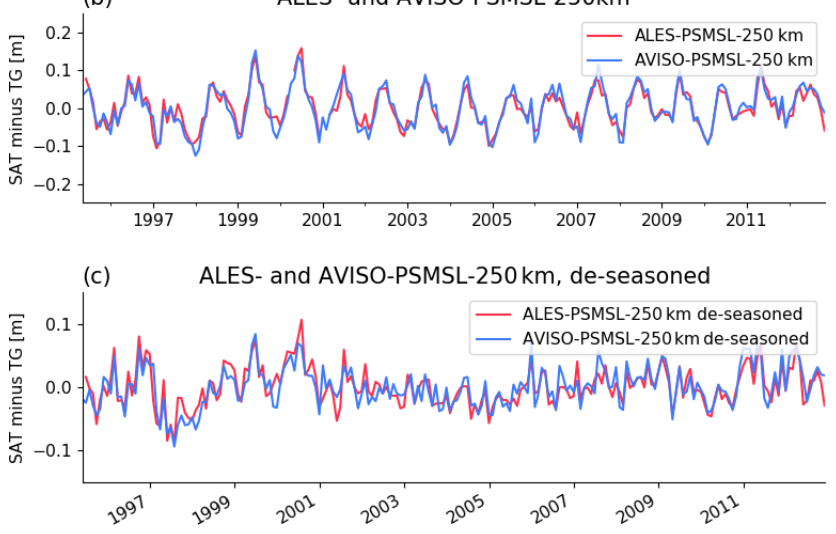

Figure 2. Shown are "SAT minus TG" time series for different datasets and configurations for the TG in Fig. 1a. (a) Monthly mean $(\mathrm{mm})$ time series for ALES-GESLA when all SLAs are averaged in a $300 \mathrm{~km}$ radius (blue) and when SLAs are comprised of the $20 \%$ most representative anomalies based on the rms SAT-TG between the altimetry and TG (red). The grey line denotes the underlying highfrequency time series. (b) Monthly mean differenced time series for ALES-PSMSL and AVISO-PSMSL, which are based on a $250 \mathrm{~km}$ radius selection of SLAs. (c) Same as (b) but with the annual and semi-annual signals removed.

\subsection{Statistical analysis: trend and uncertainty estimation}

We fit the differenced time series to a combination of a deterministic model and stochastic noise models with the maximum likelihood estimation (MLE) method. Parameters of the deterministic model are comprised of a constant offset $A$ and a linear trend $B$. The annual and semi-annual signals are expressed by harmonic functions with the annual and semiannual frequencies $\omega_{1,2}$ and amplitudes $C_{1,2}$ and $D_{1,2}$.

$y(t)=A+B t+\sum_{i=1}^{2} C_{i} \cos 2 \pi t \omega_{i}+D_{i} \sin 2 \pi t \omega_{i}$

When combining altimetry and TGs for VLM estimation, several sources can contaminate the differenced time series and inflate the actual "red" noise (low-frequency) content in the residuals, which generates autocorrelated signals in the data. The SLA computation is affected by the instrumental errors of the range estimation and of each of the geophysical corrections (Ablain et al., 2009). Such errors, as well as the measurement error of the TG itself, show up as residuals in the differenced time series. Moreover, sea level dynamics that are not common between the TG and altimeter observation locations will also contribute to the SAT-TG differences. Therefore, to avoid underestimation of the uncertainty of the parameters, we take into account autocorrelation in the residuals of the detrended and deseasoned time series. We describe the power spectral density of the noise with a combination of a power-law and a white noise model (using the Hector software; Bos et al., 2013). The power-law process assumes that time-correlated noise power is proportional to $f^{\kappa}$, which for negative spectral indices $\kappa$ describes increasing power at lower frequencies $f$ and a white noise process when $\kappa=0$ (Agnew, 1992). Santamaría-Gómez et al. (2011) showed that this combination (of a power-law and white noise model) represents the best approximation of the noise content for 275 GNSS station position time series. This combination was also implemented in studies concerned

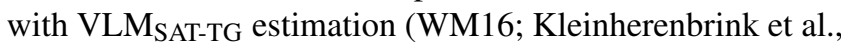
2018; Ballu et al., 2019). In particular, the spectral index $\kappa$ can contribute to detecting the intrusion of low-frequency signals in the differenced time series. Next to the spectral index $\kappa$ we estimate the individual fractions of the powerlaw and white noise models, as well as the total variance $\sigma^{2}$, which scales the amplitude of the noise. We emphasize the fact that for individual regions other noise models could be more appropriate than the implemented PL $+\mathrm{WN}$ model and would thus yield more realistic uncertainty estimates. An advanced regional spectral analysis to identify the most suitable models is, however, beyond the scope of this study.

\subsection{Validation of VLM SAT-TG $_{\text {with }}$ VLM $_{\text {GNSS }}$ trends}

To validate SAT-TG-based trend estimates, we use the ULR6a GPS solution provided by the GNSS data assembly center SONEL (Systeme d'Observation du Niveau des Eaux Littorales, http://www.sonel.org, last access: 10 December 2020). The reanalysis covers 19 years of GNSS data from 1995 to 2014, which are processed within the ITRF2008, consistent with the reference frame of altimetry orbits. The primary coordinates provided by GNSS are geocentric Cartesian coordinates $\left(X, Y, Z, V_{x}, V_{y}, V_{z}\right)$. For the comparison with vertical trends inferred from other techniques, they are converted to ellipsoidal coordinates (latitude $\phi$, longitude $\lambda$ and ellipsoidal height $\left.h ; V_{\phi}, V_{\lambda}, V_{h}\right)$. Thus, we compare GNSS ellipsoidal height trends $\left(V_{h}\right)$ with SAT-TG trends. It should be mentioned that, while the altimetry trends refer to the so-called TOPEX/Poseidon ellipsoid, the GNSS vertical trends refer to the GRS80 (Geodetic Reference System, 1980; Moritz, 2000) ellipsoid. Although there is a difference of $70 \mathrm{~cm}$ between the semi-major axes of the two ellipsoids, the GNSS and SAT vertical trends can be compared without degradation of precision, as both ellipsoids are geocentric and have the same orientation with respect to the Earth's body (e.g., the ellipsoid minor axes coincide with the Earth's mean rotation axis, and the major axes are on the Earth's equatorial plane). We take into account 

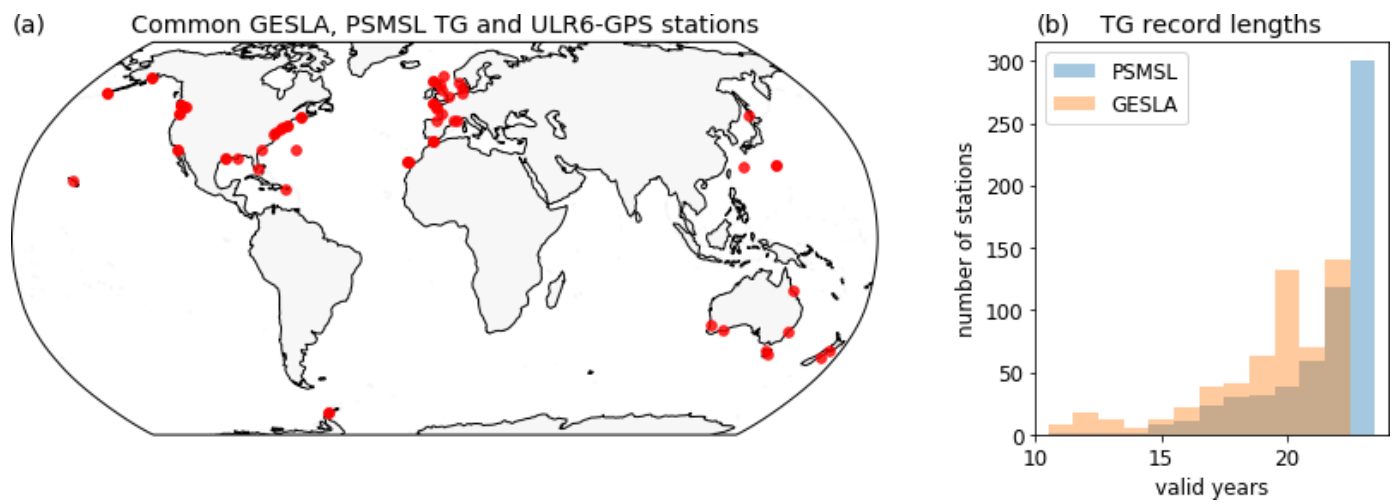

Figure 3. (a) Global distribution of 52 common GESLA, PSMSL and ULR6 GNSS stations, which meet the described requirements. (b) Number of TG stations sorted by the number of months which contain valid data (here shown in valid years) in the period 1993-2015.

GNSS stations which are closer than $1 \mathrm{~km}$ to a TG. With this constraint we aim to avoid potential differential vertical motions between the TG and the GNSS antenna (WM16).

The TG locations and record lengths differ among the presented experimental datasets (Sect. 3.1). Therefore, we define several requirements for the validation of those experimental datasets to obtain a consistent set of TG and GNSS validation pairs. In contrast to PSMSL records GESLA TG observations only last until 2015. Even when PSMSL TG records are limited to before 2015, they still contain more months of valid data than GESLA (see Fig. 3b). Hence, we align the time period covered by the PSMSL TGs to the corresponding GESLA TGs for all following experimental datasets. Generally, we only take into account SATTG time series when they cover at least 120 months of valid data. Note that the outlier analysis (Sect. 2.4) or coupling of high-frequency TG data in the ZOI can reduce the length of the SAT-TG time series for GESLA TGs. Taking into account all these requirements, we obtain 52 common GESLA and PSMSL TGs that provide a neighboring GNSS station within $1 \mathrm{~km}$ distance. These pairs are validated for ALES-PSMSL-250 km, ALES-GESLA$250 \mathrm{~km}$ and AVISO-PSMSL-250 km. The ALES-GESLAZOI combination includes six more stations. The resulting validation pairs are shown in Fig. 3a, where a higher coverage in northerly and midlatitude regions is evident.

We compute the rms $\triangle \mathrm{VLM}$ and the median of the differences $(\Delta V L M)$ of VLM SAT-TG $_{\text {and }}$ VLM $_{\text {GNSS }}$ for a given dataset combination. To take into account the derived formal errors $(U)$ of the estimate we compute the weighted $\mathrm{rms}_{\mathrm{w}}$ as follows:

$\mathrm{rms}_{\mathrm{w}}=\sqrt{\sum_{i=1}^{n}\left(w_{i}\left(\mathrm{VLM}_{\mathrm{GNSS}_{i}}-\mathrm{VLM}_{\mathrm{SATTG}_{i}}\right)^{2}\right)}$, with weights

$$
w_{i}=\frac{\sqrt{\left(U_{\mathrm{GNSS}_{i}}^{2}+U_{\mathrm{SATTG}_{i}}^{2}\right)}}{\sum_{i=1}^{n}\left({\sqrt{\left(U_{\mathrm{GNSS}_{i}}^{2}+U_{\mathrm{SATTG}_{i}}^{2}\right)}}^{-1}\right)} .
$$

We also analyze the median of the absolute value of differences $(|\Delta \mathrm{VLM}|)$. This metric is less prone to extreme deviations and can thus consolidate the evaluation of the dataset performances. We generally assume that GNSS provides a more accurate estimation of the linear component of the VLM with a smaller error than VLM SAT-TG $_{\text {, despite a shorter }}$ time span of measurements. Hence, for the purposes of this paper and as done in all studies concerning VLM $_{\text {SAT-TG }}$ estimation, we define as measures of accuracy the $\mathrm{rms}_{\triangle \mathrm{VLM}}$ and additionally the median of $|\Delta \mathrm{VLM}|$. We include the spectral index $\kappa$ (see Sect. 3.3) as it helps to understand the level of autocorrelation of the time series. All statistics other than the rms $\triangle \mathrm{VLM}$ denote median values (of all VLM $\mathrm{VAT}_{\mathrm{SATG}}$ estimates) for a specific dataset configuration.

\section{Results}

\subsection{Comparison of different dataset configurations based on a $250 \mathrm{~km}$ average selection}

We compare the performances of the three datasets which are constructed from $250 \mathrm{~km}$ radius SLA averages in Table 2 . Validation against GNSS vertical velocities reveals that the gridded combination AVISO-PSMSL- $250 \mathrm{~km}$ slightly outperforms ALES-PSMSL-250 km in terms of accuracy. Both the $\mathrm{rms}_{\triangle \mathrm{VLM}}$ and the median of absolute trend differences are $9 \%$ lower for AVISO-PSMSL-250 km. This confirms that, if all the available altimetry data within a wide region are compared against monthly values of TGs, the use of a gridded product outperforms the along-track performances (WM16). Kleinherenbrink et al. (2018) similarly compared 


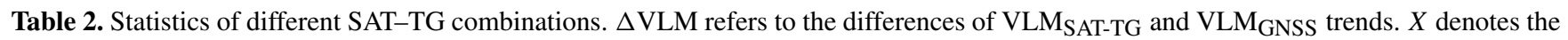
relative level of comparability above which data are included.

\begin{tabular}{|c|c|c|c|c|c|c|}
\hline$X$ & $\begin{array}{r}\mathrm{rms}_{\Delta \mathrm{VLM}} \\
\mathrm{mm} \mathrm{yr}^{-1}\end{array}$ & $\begin{array}{r}\text { Weighted } \mathrm{rms}_{\Delta \mathrm{VLM}} \\
\mathrm{mm} \mathrm{yr}^{-1}\end{array}$ & $\begin{array}{r}\text { Med. }|\Delta \mathrm{VLM}| \\
\mathrm{mm} \mathrm{yr}^{-1}\end{array}$ & $\begin{array}{r}\text { Med. } \Delta \text { VLM } \\
\mathrm{mmyr}^{-1}\end{array}$ & Med. uncertainty & Spectral index $\kappa$ \\
\hline & \multicolumn{6}{|c|}{ ALES-PSMSL-250 km (52 stations) } \\
\hline & 1.68 & 1.57 & 1.28 & -0.87 & 0.69 & -0.39 \\
\hline & \multicolumn{6}{|c|}{ AVISO-PSMSL-250 km (52 stations) } \\
\hline & 1.50 & 1.48 & 1.12 & 0.56 & 0.73 & -0.56 \\
\hline & \multicolumn{6}{|c|}{ ALES-GESLA-250 km (52 stations) } \\
\hline & 1.51 & 1.47 & 1.14 & -0.39 & 0.79 & -0.39 \\
\hline & \multicolumn{6}{|c|}{ ALES-GESLA-ZOI (best rms SAT-TG, 58 stations) } \\
\hline 0 & 1.54 & 1.45 & 0.98 & -0.46 & 0.86 & -0.45 \\
\hline 0.1 & 1.39 & 1.36 & 0.9 & -0.27 & 0.86 & -0.44 \\
\hline 0.2 & 1.34 & 1.33 & 0.88 & -0.36 & 0.83 & -0.47 \\
\hline 0.3 & 1.32 & 1.36 & 0.83 & -0.44 & 0.78 & -0.46 \\
\hline 0.4 & 1.3 & 1.38 & 0.87 & -0.37 & 0.76 & -0.45 \\
\hline 0.5 & 1.29 & 1.4 & 0.86 & -0.26 & 0.73 & -0.47 \\
\hline 0.6 & 1.3 & 1.43 & 0.87 & -0.31 & 0.71 & -0.47 \\
\hline 0.7 & 1.28 & 1.39 & 0.82 & -0.41 & 0.66 & -0.48 \\
\hline 0.8 & 1.28 & 1.37 & 0.86 & -0.41 & 0.58 & -0.43 \\
\hline 0.9 & 1.53 & 1.58 & 0.97 & -0.43 & 0.61 & -0.46 \\
\hline
\end{tabular}

an along-track combination of $250 \mathrm{~km}$ SLA averages (from RADS) and PSMSL TG data with the AVISO-PSMSL combination from WM16. They found a small $\mathrm{rms}_{\triangle \mathrm{VLM}}$ reduction of $0.1 \mathrm{~mm} \mathrm{yr}^{-1}$ when using the along-track product without any correlation thresholds applied. WM16's trends were, however, based on $1^{\circ}$ radius averages of SLAs (in contrast to the $250 \mathrm{~km}$ selection), and record lengths were not equalized as in this study.

For both combinations the median of the VLM differences (ALES-PSMSL-250 km: $-0.87 \mathrm{~mm} \mathrm{yr}^{-1}$; AVISO-PSMSL$250 \mathrm{~km}$ : $0.56 \mathrm{~mm} \mathrm{yr}^{-1}$ ) deviates from values shown in previous studies (WM16, $-0.25 \mathrm{~mm} \mathrm{yr}^{-1}$; Kleinherenbrink et al., $\left.2018,-0.06 \mathrm{mmyr}^{-1}\right)$. In contrast to these previous estimates, we use different spatial selection scales of SLAs, smaller numbers of TG-GNSS pairs and deviating record lengths, which impedes a direct comparison. Moreover, the altimetry datasets might be affected by instrumental drifts. In this respect, differences among the datasets may be caused not only by different techniques applied to reduce intermission biases (e.g., the MMXO approach for ALES), but also by different missions incorporated in the records. Note that in contrast to ALES, AVISO contains TOPEX, which has also been shown to be affected by a strong drift (Watson et al., 2015). Still, the observed rms $\triangle$ VLM of AVISOPSMSL-250 km (1.50 $\left.\mathrm{mm} \mathrm{yr}^{-1}\right)$ is comparable to the WM16 result $\left(1.47 \mathrm{~mm} \mathrm{yr}^{-1}\right)$. In contrast to trend accuracies, the uncertainties are $5 \%$ lower for ALES-PSMSL-250 km than for AVISO-PSMSL-250 km. As in WM16, the spectral in- dex $\kappa$ of the interpolated gridded product is lower than for the along-track data. Both $\kappa$ indices $(-0.56$ and -0.39$)$ also match those found by WM16 well for AVISO $(-0.5)$ and the along-track product $(-0.4, \mathrm{GSFC})$. The larger spectral index $(-0.39)$ is associated with reduced power of the noise at low frequencies and thus indicates reduced contamination of the SLA signal by sea level variations that do not represent those measured at the TG. This enhanced comparability is also reflected in the lower trend uncer-

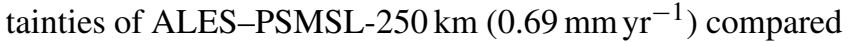
to AVISO-PSMSL-250 km $\left(0.73 \mathrm{~mm} \mathrm{yr}^{-1}\right)$. The differences between the characteristics of the residuals of the datasets can partially be explained by the resolution of the data: due to the spatial filtering of the data, the gridded solution AVISO incorporates information on SLAs beyond the $250 \mathrm{~km}$ radius and thus contains time-correlated SL signals with stronger deviations from the TG records.

In comparison with the low-frequency datasets (ALESPSMSL-250 km and AVISO-PSMSL-250 km), the high-rate setup ALES-GESLA-250 km improves the rms $\triangle$ VLM. The absolute bias of trend differences decreases more substantially to $0.39 \mathrm{~mm} \mathrm{yr}^{-1}$ (compared to $-0.87 \mathrm{~mm} \mathrm{yr}^{-1}$ ). Compared to ALES-PSMSL-250 km, we find increased trend uncertainties for ALES-GESLA-250 km, which can be partially explained by higher power-law variance of this GESLA-based configuration. Although trend uncertainties are higher for the ALES-GESLA-250 km configuration, we choose this setup to investigate the impact of the ZOI. This 

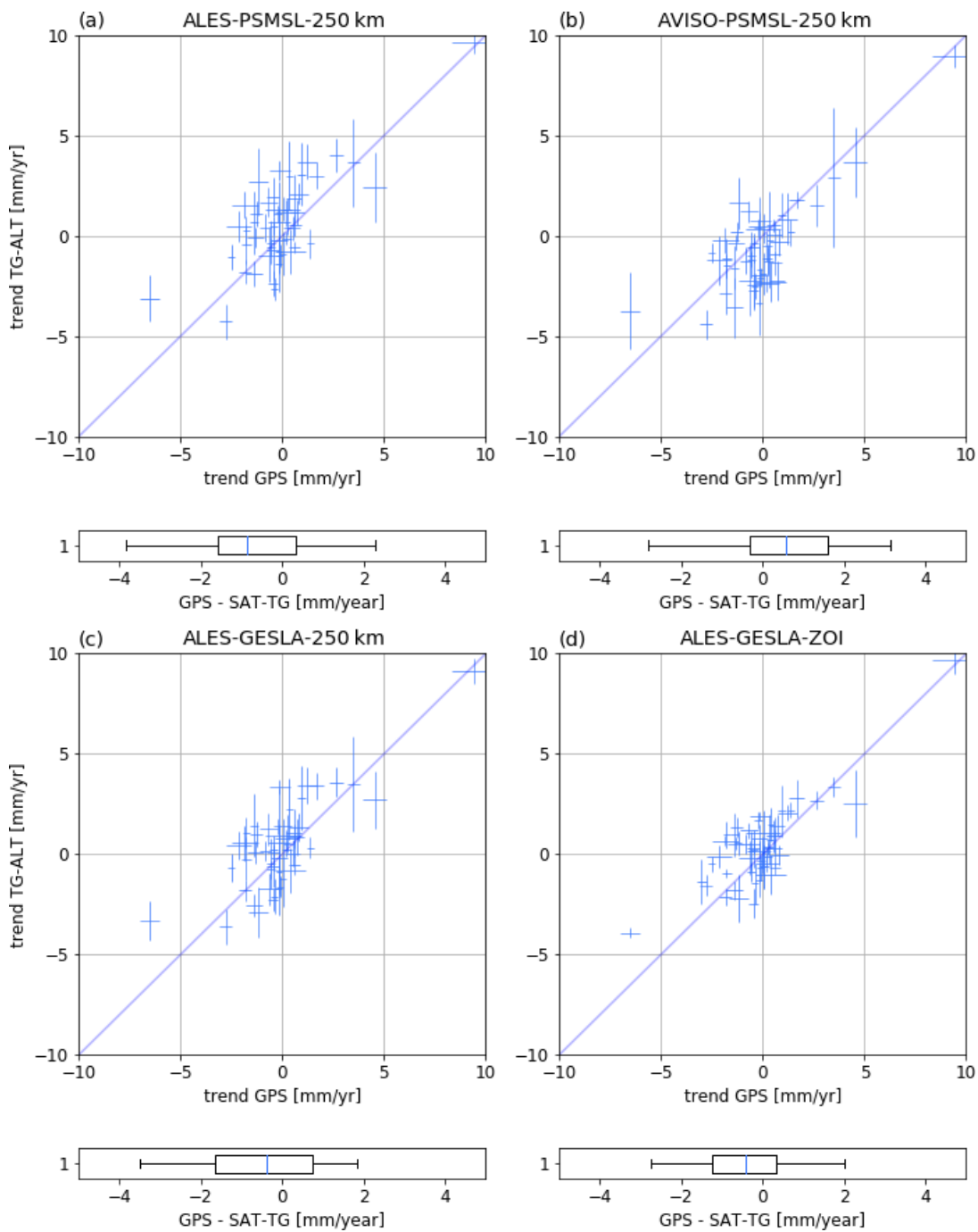

Figure 4. Scatter and box plots comparing estimated SAT-TG trends and GNSS trends, as in WM16 Fig. 14. (a) ALES-PSMSL-250 km, (b) AVISO-PSMSL-250 km, (c) ALES-GESLA-250 km and (d) ALES-GESLA-ZOI (at $20 \%$ threshold based on the rms criterion). Error bars denote the $1 \sigma$ trend uncertainties of the individual estimates.

dataset provides better results concerning trend accuracy (weighted or unweighted rms) and has a lower median bias. Moreover, using the high-frequency data, we are able to couple SAT and TG observations at much higher temporal resolution than would be the case when using monthly PSMSL data. Therefore, the ALES-GESLA coupling is further developed based on a better definition of the ZOI in the next section.

\subsection{The zone of influence improves VLM estimates}

We investigate how the ZOI selection of SLAs fosters quality SAT-TG VLM estimates. As addressed in Sect. 3.2, we build the ZOI upon different criteria of comparability: rmssAT-TG, correlation and the residual annual cycle. First, we focus on the results of using the rmsSAT-TG of the detrended differenced time series (Table 2 and Fig. 4, ALES-GESLA-ZOI).
We observe that the rms $\triangle \mathrm{VLM}$, the median of absolute and total differences, and trend uncertainties decrease towards higher relative thresholds. The statistics converge to a minimum when the ZOI is restricted to the $30 \%-20 \%$ best data. To compare ALES-GESLA-ZOI with the other dataset combinations, we compute the statistics for the same 52 TGs used in these configurations (because the shown statistic in Table 2 refers to a larger set of 58 stations). At the $20 \%$ thresholds, we obtain similar performances with an rms $\triangle \mathrm{VLM}$ of $1.29 \mathrm{~mm} \mathrm{yr}^{-1}$, median uncertainty of $0.51 \mathrm{~mm} \mathrm{yr}^{-1}$ and a median of absolute differences $(|\Delta \mathrm{VLM}|)$ of $0.86 \mathrm{~mm} \mathrm{yr}^{-1}$. Thus, the improvements of $\mathrm{rms}_{\triangle \mathrm{VLM}}$ compared to the plain $250 \mathrm{~km}$ radius selection (ALES-GESLA-250 km) are $15 \%$ and $35 \%$ for uncertainties. Hence, we find more substantial, nearly linear reductions of trend uncertainty with increasing relative thresholds compared to trend accuracy $\left(\mathrm{rms}_{\triangle \mathrm{VLM}}\right.$, 
Table 2, ALES-GESLA-ZOI). As demonstrated for different time series in Fig. 2, selecting, e.g., highly correlated SLAs efficiently reduces the noise of the residuals. Correspondingly, at higher levels of comparability, the variance, which scales the amplitudes of the considered noise models, decreases (not shown).

Because the spectral index (for ALES-GESLA-ZOI) is slightly lower ( -0.43 at $20 \%$ level) than for ALES-GESLA$250 \mathrm{~km}(-0.39)$ it cannot account for the uncertainty improvements. Here, the lower $\kappa$ index reveals a relative increase in power at low frequency (i.e., timescales longer than months). Thus, the bulk of improvements we see in uncertainty (comparing ALES-GESLA-ZOI and ALES-GESLA$250 \mathrm{~km}$ ) stems from the reduction of the power-law and white noise amplitudes in the residuals. This is in turn caused by improvements of the comparability of TG and altimetry measurements at high frequency (i.e., days). We argue that extending the maximal radius selection from 250 to $300 \mathrm{~km}$ to construct the ZOI (as done for ALES-GESLA-ZOI) increases the low-frequency noise (indicated by $\kappa$ ). However, with this selection we capture more altimetry tracks with similar highly correlated high-frequency signals (see Fig. 1), which again contribute to sampling density and reduced white noise. This further substantiates our choice to select SLA within a larger $300 \mathrm{~km}$ radius, which is also supported by observed larger-scale coherency of coastal sea level trends (see Sect. 3.2).

The $\mathrm{rms}_{\triangle \mathrm{VLM}}$ and trend uncertainty level off at very high thresholds and ultimately increase when only $5 \%$ of the data is used (Fig. 5a and c). We argue that this is mainly related to a decrease in sampling density of the time series included in the selection: at the 95th percentile, the median sample size (i.e., number of monthly averages in a time series) is $20 \%$ smaller that the sample size at the 80th percentile. Robust trend estimates require a minimum of samples; hence, using a reduced number of along-track data time series, even when they show a maximum degree of comparability, yields on a global average decreased trend accuracy $\left(\mathrm{rms}_{\triangle \mathrm{VLM}}\right)$. We thus argue that the optimum threshold identified at about the 80th percentile (of the data sorted by rms) represents a compromise between data comparability and the sampling density of altimetry data. We emphasize the fact that there are numerous factors, other than the time period covered, which may contribute to a lack of comparability of SAT-TG and GNSS trends. We further elaborate those in the subsequent discussion in Sect. 5.

When setting this optimal threshold to $20 \%$, the ALESGESLA-ZOI setup outperforms the other investigated configurations. Figure 4 compares the scatter of estimated

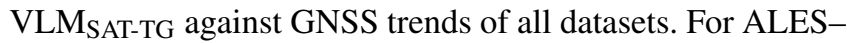

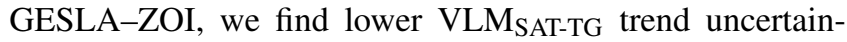
ties and reduced spread of the estimates with respect to the $1: 1$ line (Fig. 4). These results underpin the fact that a refined selection procedure (ZOI) represents the dominant advancement, as this approach outstrips the improvements (in terms of trend accuracy and uncertainty) which are obtained from using different altimeter or TG data combinations.

Figure 5a and c illustrate the influence of applying different criteria to the performance of estimated trends. Generally, increasing relative rmsSAT-TG or correlation thresholds yields similar optimal ranges $(\sim 20 \%)$ for both $\mathrm{rms}_{\triangle \mathrm{VLM}}$

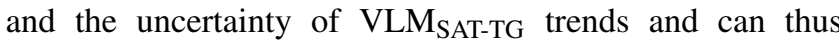
be interchangeably used. At lower relative threshold levels (20\%-60\%), however, application of the rms criterion yields slightly reduced $\mathrm{rms}_{\triangle \mathrm{VLM}}$ values compared to correlations. Hence, for this set of TGs an SLA selection based on the minimum rmsSAT-TG generally provides more accurate trend estimates (in terms of rms $\triangle \mathrm{VLM}$ ). The residual annual cycle criterion only weakly reproduces the improvements provided by the other criteria and is less suited to define the ZOI. This observation emphasizes the need for matching the data according to the high-frequency comparability (rms, correlation) because selecting the data based on the residual annual cycle (i.e., low-frequency comparability) limits the performance of the estimates (Fig. 5c). Considering improvements in the bias of trend differences, we find no significant differences in using different thresholds. In contrast to the improvements in accuracy (as shown in Fig. 5), the median $\triangle$ VLM does not converge to a global optimum. Therefore, we discuss the contribution of other factors affecting the comparability of SAT and GNSS in Sect. 5.2.

\section{Discussion}

The integration of the ZOI primarily reduces the uncertainty of VLM VAT-TG $_{\text {trend estimates. Over a considerable range }}$ of thresholds ( $80 \%-20 \%$ of best-performing data) trend accuracies do not improve as strongly as the uncertainties decrease. This is in line with Kleinherenbrink et al. (2018), who showed that for a highly correlated subset of TGs, increasing absolute correlation thresholds would not significantly reduce the rms ${ }_{\triangle \mathrm{VLM}}$. We thus strive to better understand why trend estimates do not always improve when selecting highly comparable (with respect to TG) or closely located absolute SLA measurements. This question ultimately leads to the discussion of the importance of identifying the small-scale dynamical components of local sea level variability, given that long-term absolute sea level trends are large-scale signals.

\subsection{Space and time dependencies of coastal sea level trends}

The results presented in Fig. 5 and Table 2 denote metrics and performances derived from the global TG-GNSS dataset for ALES-GESLA-ZOI and support an optimal threshold at $20 \%$. It remains to be investigated whether the described optimum global threshold also reflects the best choice at every coastal site considered. Therefore, we investigate at which relative levels individual $\mathrm{VLM}_{\mathrm{SAT}-\mathrm{TG}}$ and $\mathrm{VLM}_{\mathrm{GNSS}}$ trend 


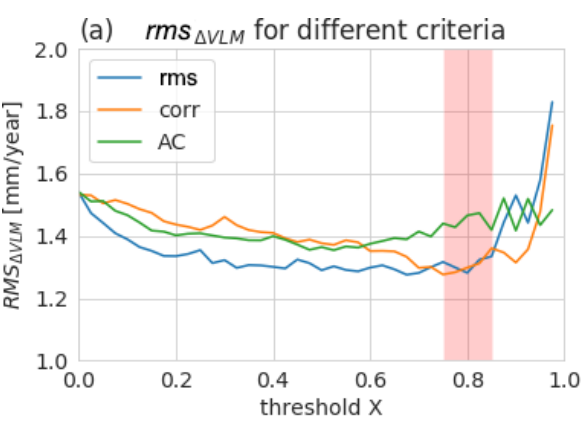

(c) VLM $M_{S A T-T G}$ trend uncertainties

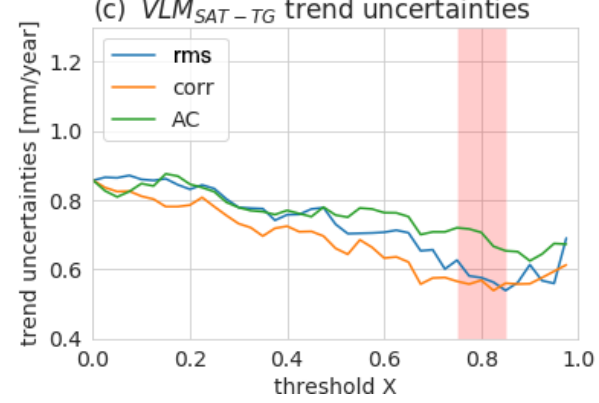

(b) Local optimal thresholds

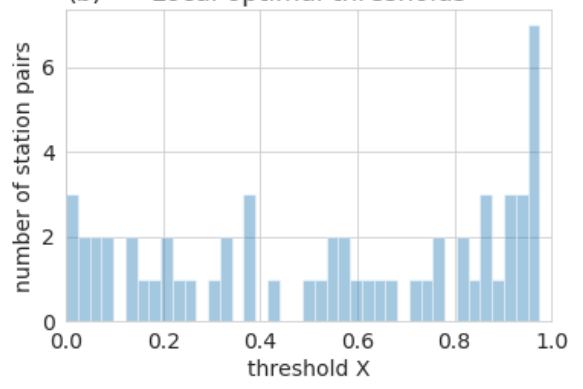

(d) Median distance to coast

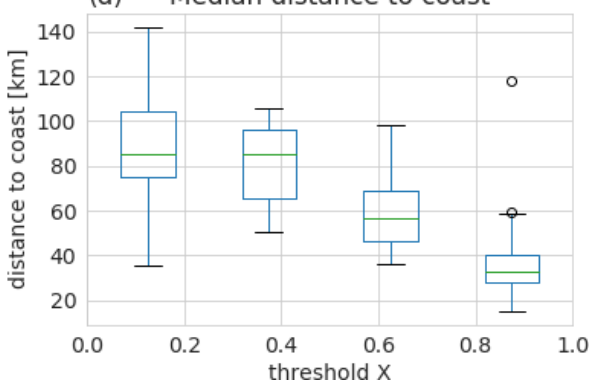

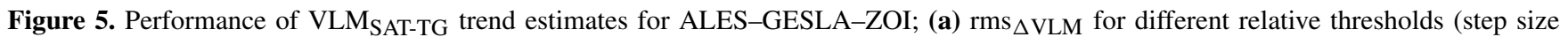
$2.5 \%$ ) and different selection criteria: rms SAT-TG (blue), correlation (red) and residual annual cycle (AC, green). (c) Same as (a) but for median uncertainty. (b) Distribution of best-performing relative thresholds for individual stations. The local optimal threshold is defined at

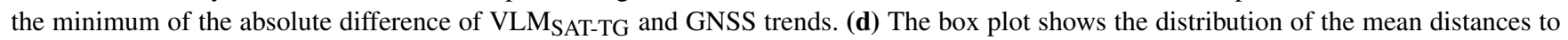
the coast for the individual optimum ZOIs as denoted in (b). The distances refer to the distributions within the $0 \%-25 \%$ and $25 \%-50 \%$ levels.

estimates yield the smallest absolute deviations. Postulating that the actual VLM at the TG location is linear and perfectly detected by the GNSS station, these thresholds denote the "local" optimal levels. With this analysis, we aim to better understand the spread of individual optimal ZOIs and what would be the best theoretically achievable $\mathrm{rms}_{\triangle \mathrm{VLM}}$. This analysis also provides a basis to motivate future investigations, in particular to identify systematic factors that may lead to locally different extents of the ZOI, and to improve the accuracy of trend estimates.

Figure $5 \mathrm{~b}$ displays the distribution of local optimal thresholds for TG-GNSS stations for the ALES-GESLA-ZOI dataset. Note that these estimates are not independent as they are based on prior knowledge of the ground-truth VLM from GNSS. Overall, the optimal levels $X$ are broadly distributed from 0 to 0.975 . We find the highest concentrations between 0.8 and 0.975 , which slightly exceeds the range of the global optimum. At the global optimum itself ( 0.8 based on correlations), the median distance to the coast (of all SLA measurements in a ZOI) is $39.4 \mathrm{~km}$. A total of $25 \%$ of the altimeter observations are within a range of $20 \mathrm{~km}$ to the coast, i.e., the region with the most pronounced coastal advancements of the along-track dataset (Passaro et al., 2015).

In contrast to these examples, we find very low local optima for some stations (Fig. 5b). Here, local VLM SAT-TG and GNSS trend differences do not converge to a minimum when increasing the comparability of SAT and TG observations. Accordingly, in these cases, vertical land motion estimates do not necessarily benefit from high coastal resolution of the data because a low relative threshold is simultaneously linked to a larger-scale selection of SLAs (Fig. 5d). At the lowerlevel ranges, for instance at 0-0.2, SLAs have an average distance of $95 \mathrm{~km}$ to the coast. Supposing that the sources of these larger scales of coherency of coastal SL trends were known, a more advanced adaption to these additional factors would further increase the accuracy of VLM estimates. An associated ideal selection of trends, based on optimal individual levels shown in Fig. 5d, would largely reduce rms $_{\Delta \text { VLM }}$ to $0.89 \mathrm{~mm} \mathrm{yr}^{-1}$. We emphasize the fact that this constitutes the best rms that could theoretically be achieved with our dataset combination if all of the local optimal levels could be systematically explained. This demonstrates that, although there might be room for minor improvements, there is still a strong limitation remaining in bringing the rms below $1 \mathrm{~mm} \mathrm{yr}^{-1}$.

To further shed light on the relationships between dynamical sea-level-based SLA selection and spacial coherence of trends and uncertainties, we show trend and uncertainty maps (Fig. 6) in accordance with those in Fig. 1 (displaying maps of statistical criteria). Here, we map linear trends and uncertainties onto observed levels of comparability defined by the correlation criterion. We thus compute these VLM SAT-TG $_{\text {S }}$ trends over different coastal regions (see further details in 
(a)

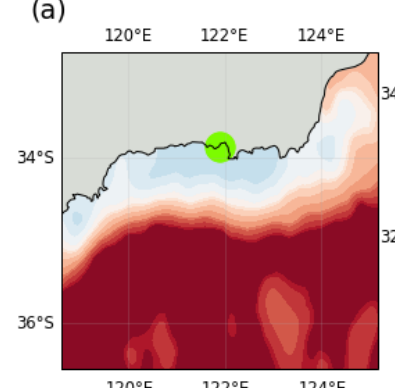

(b)
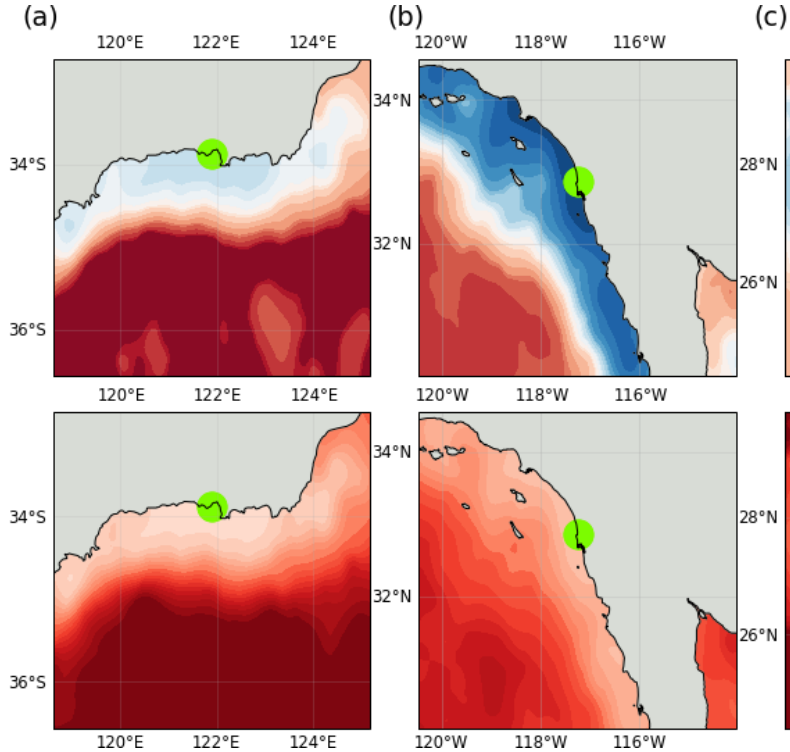

(c)
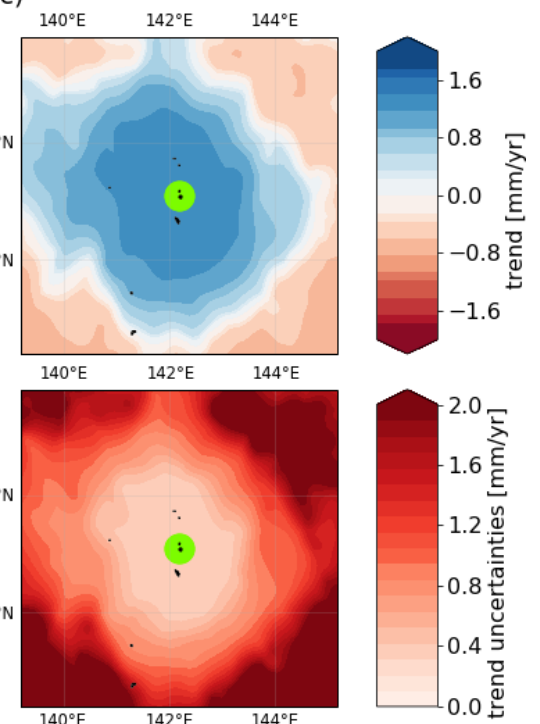

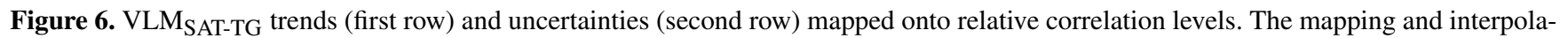
tion method is further elucidated in Appendix A. We show the same stations (a-c) as in Fig. 1.

Appendix A). As a result, we observe sharp trend gradients consistent with the degree of comparability: Fig. 6a, for instance, shows high small-scale variability of trends because trends of the slope-current region are detached from the trends in the alongshore continental shelf region. Trends in Fig. 6a and b project onto the far-reaching alongshore correlations as observed in Fig. 1, showing consistent signals over several hundred kilometers along the coast. Uncertainty maps further emphasize the importance of the application of highly resolved coastal altimetry data (Fig. 6, lower row). These examples show that at individual locations the use of less comparable SLAs can increase the uncertainty by a factor of 3 to 4 . Therefore, for the majority of cases, these results promote using high relative levels of comparability to define the ZOI for trend estimation. However, we also observe that the coherency of trends (highlighted by the strength of absolute trend gradients) can be differently expressed at different coastal regions.

Bathymetric and coastal properties can cause large discrepancies in responses of coastal sea level variability as they modify the character of the impact of large-scale atmospheric forcing and remote variability from the deeper ocean (Woodworth et al., 2019). Hence, an advanced analysis of SL coherency and the role of bathymetry might facilitate further enhancements of trend accuracy based on SAT and TG. We note that physical origins might, however, not necessarily cause the spread of individual optimal thresholds (Fig. 5b). If our assumption that GNSS trend estimates perfectly represent the linear trend over the time span of the altimetry and TG records was not met, the shown individual thresholds would erroneously reflect local optima. Ruling out these sources of error is thus a prerequisite to further study physical explanations for different extents of the ZOI.

Next to site-dependent physical factors, the spatial scales of trend coherency might also depend on the time span of the observations themselves. Global maps of sea level trends, for example, even when derived from 2 decades of observations, still show distinct patterns of natural and forced variability and thus overshadow signals of ocean mass or steric contributions (e.g., Stammer et al., 2013). Similarly, coastal sea level trends that are computed in the ZOI are affected by local interannual sea level variability on top of the secular trend. Therefore, the importance of adopting the concept of the ZOI for improving trend accuracy might also be influenced by the actual time span covered by the record.

To investigate this timescale dependency, we truncate the

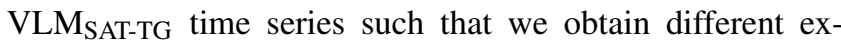
perimental ALES-GESLA-ZOI sets with maximum record lengths from 10 to 18 years. We repeat the same validation analysis against GNSS trends as in Sect. 4. Figure 7a encompasses anomalies of the $\mathrm{rms}_{\triangle \mathrm{VLM}}$ with respect to the mean $\mathrm{rms}_{\triangle \mathrm{VLM}}$ for a dataset of a specific timescale, which is given in Fig. 7b (red). The same evolution is shown for trend uncertainties in Fig. 7c.

Mean $\mathrm{rms}_{\triangle \mathrm{VLM}}$ and mean uncertainties (which are averaged over all relative thresholds for a specific maximum record length) substantially decrease with increasing record length (Fig. 7a and c). Both statistics approximately follow the theoretical proportionality of uncertainty and sample size $n$ of $1 / \sqrt{n}$ (assuming no serial correlation). The evolution of the rms $\triangle \mathrm{VLM}$ anomaly shows that selecting SLAs in a ZOI at high relative thresholds more substantially reduces the $\mathrm{rms}_{\triangle \mathrm{VLM}}$ on shorter timescales (e.g., 10 years) 

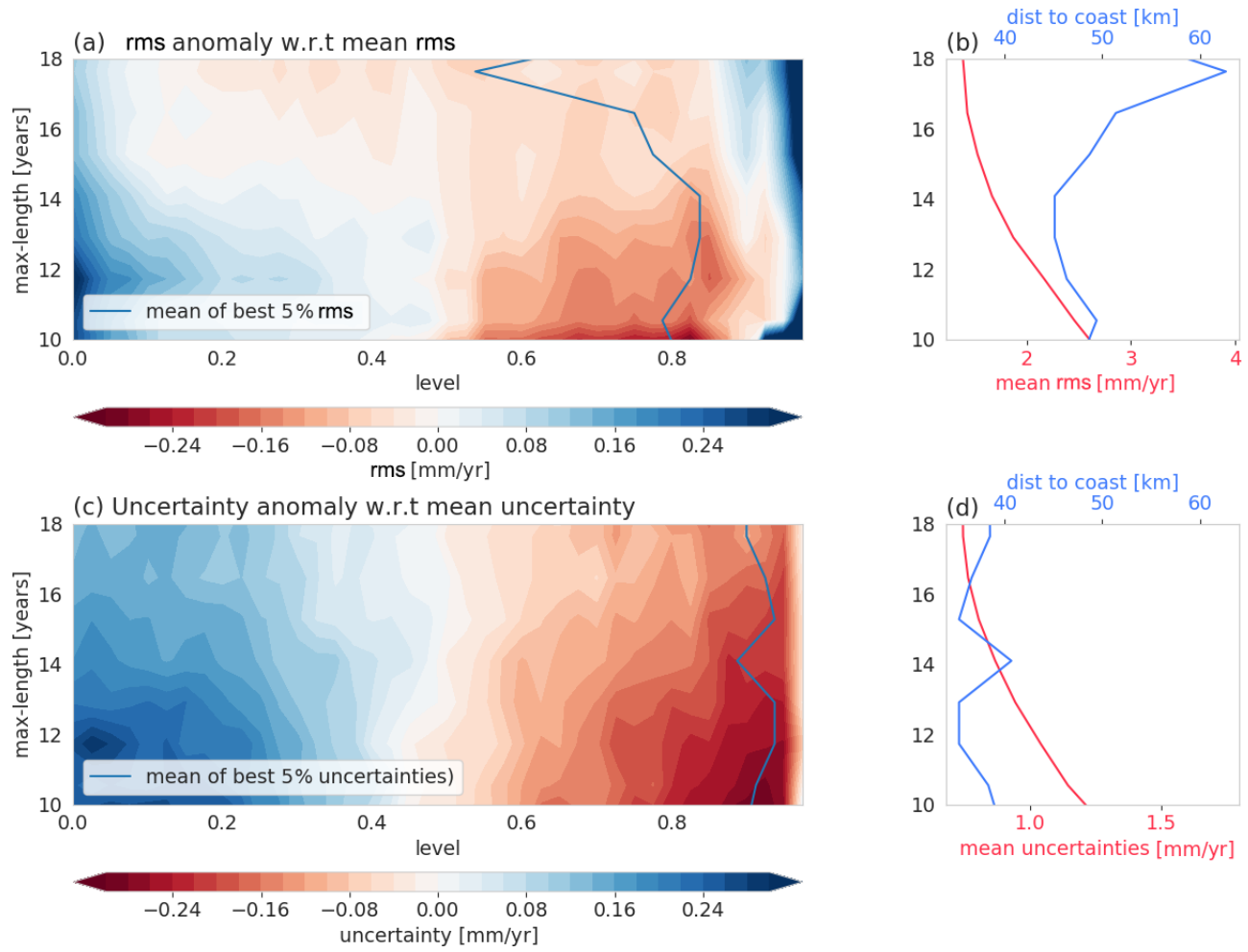

Figure 7. Time and space dependencies of trend uncertainty and accuracies: (a) evolution of the rms $\triangle$ VLM anomaly (SAT-TG vs. GNSS trend) for subsets of ALES-GESLA-ZOI, depending on a relative threshold $X$ ( $x$ axis) and a maximum record length ( $y$ axis). The rms $\Delta$ VLM anomaly is defined as the departure from the mean rms $\triangle \mathrm{VLM}$ (shown in b) averaged over all thresholds $X$ for a specific maximum record length. In (b) we also show in blue the mean distance to the coast of the measurements, associated with the average of the best $5 \% \mathrm{ZOI}$ levels per timescale, shown in (a). (c, $\mathbf{d})$ Same as $(\mathbf{a}, \mathbf{b})$ but for uncertainties.

than on longer timescales (Fig. 7a, e.g., at 18 years). At long timescales, the rms $\triangle \mathrm{VLM}$ anomalies do not significantly improve between the $80 \%$ and $20 \%$ thresholds, which we also observe in the previous analysis in Fig. 5a. We argue that the transition timescale on which the improvements of $\mathrm{rms}_{\triangle \mathrm{VLM}}$ flatten (14-16 years) marks when the high-frequency coastal sea level dynamical variability is superseded by dynamics producing large-scale sea level trends. In other words, this is the timescale on which coastal sea level trends start to merge with the offshore trends. The tendency of increasing spatial scales with time is also reflected by the increasing distances to the coast of the measurements for an optimal ZOI at a specific timescale (Fig. 7b). The timescale dependency could explain the mismatch of trend accuracy and uncertainty improvements when using higher levels of comparability. This is also supported by Kleinherenbrink et al. (2018), who showed little sensitivity for SAT-TG combinations which had minimum lengths of 15 years.

The same evaluation for the dependency of uncertainty on time and level of comparability $X$ demonstrates that using the ZOI nearly constantly improves trend uncertainties at any timescale. Hence, even though spatial scales of trend coherency might increase with time, an ideal match of altimetry and TGs should be based on a ZOI.

\subsection{Systematic errors}

VLM estimates from different datasets (e.g., AVISOPSMSL-250 km and ALES-GESLA-ZOI) are biased compared to trends inferred from GNSS observations. Based on Monte Carlo simulations (see Appendix Fig. B1) we argue that these biases are significant for most of the dataset combinations (ALES-PSMSL-250 km, AVISO-PSMSL-250 km, ALES-GESLA-ZOI). In the following, potential sources of these biases will be discussed.

Next to the record length (see Sect. 5.1), systematic errors critically affect the accuracy of the SAT-TG technique and can have strong systematic effects on the trend differences. Limiting factors for VLM determination from both SATTG and GNSS observations are the accuracy and uncertainty of the origin and scale of the reference frame (see WM16; Collilieux and Woppelmann, 2009; Santamaría-Gómez et al., 2012), which cannot be realized yet at the required accuracy level (Bloßfeld et al., 2019).

Moreover, as mentioned before, the multi-mission calibration applied (MMXO) reduces intermission biases and regionally coherent systematic errors but does not feature a calibration against TG. The median bias identified for ALESGESLA-ZOI could be affected by a drift of the mission used 
as a reference. In contrast, the AVISO dataset does not include time-dependent intermission biases and might therefore be additionally influenced by systematic effects of, e.g., Envisat or Sentinel-3a (Dettmering and Schwatke, 2019).

Next to altimeter bias drift, nonlinear VLM from contemporary mass redistribution (CMR) changes was shown to cause differences between VLM $\mathrm{SAT}$-TG and $\mathrm{VLM}_{\mathrm{GPS}}$ due to the different time periods covered (e.g., Kleinherenbrink et al., 2018). Using GRACE (Gravity Recovery and Climate Experiment) observations Frederikse et al. (2019) demonstrated that associated deformations can cause VLM trends on the order of $1 \mathrm{~mm} \mathrm{yr}^{-1}$. Therefore, they introduced a new method to reduce VLM $_{\mathrm{GPS}}$ by GIA and CMR signals to minimize their associated induced extrapolation biases. Kleinherenbrink et al. (2018) incorporated nonlinear VLM from CMR to assess the corresponding trend differences between VLM $_{\text {SAT-TG }}$ and VLM GPS. They reveal that VLM $_{\text {SAT-TG }}$ estimates are lower than VLM $_{\mathrm{GPS}}$ in many parts of North America and Europe and higher in subtropical and tropical regions as well as Australia and New Zealand (refer to Fig. 9 in Kleinherenbrink et al., 2018). Because northerly regions like North America are affected by dynamic changes in CMR, GNSS observations which cover shorter and more recent time spans than satellite altimetry detect stronger uplift signals. For a set of 155 TG-GNSS pairs, integration of these signals slightly reduced the median bias from -0.14 to $-0.07 \mathrm{~mm} \mathrm{yr}^{-1}$ but had no significant effect on $\mathrm{rms}_{(\Delta \mathrm{VLM})}$. Given that most of the TG-GNSS stations used in this study are located in Europe, North America and Australia, CMR might also alleviate the negative trend bias of ALESGESLA-ZOI. Therefore, extending the validation platform, not only by using other homogeneous GNSS observations but also GRACE and GIA estimates, would strongly support identification and mitigation of such systematic errors.

\subsection{Comparison with previous results}

Based on optimal relative thresholds, we estimated an $\mathrm{rms}_{\triangle \mathrm{VLM}}$ between SAT-TG and GNSS trends of $1.28 \mathrm{~mm} \mathrm{yr}^{-1}$ and a median uncertainty of $0.58 \mathrm{~mm} \mathrm{yr}^{-1}$ at 58 sites. Our approach of combining along-track altimetry, high-frequency TG data and a refined SLA selection scheme improves the performance of VLM estimation compared to using gridded altimetry products and constant spatial SLA averages (WM16 $\mathrm{rms}_{\triangle \mathrm{VLM}}$ : $1.47 \mathrm{~mm} \mathrm{yr}^{-1}$; uncertainty $0.80 \mathrm{~mm} \mathrm{yr}^{-1}$ ). Other studies further emphasized the importance of spatial resolution in coastal zones, considering the decreasing temporal and spatial scales of sea level variability in such areas. With a focus on coastal sea level trends, Cipollini et al. (2017) demonstrated that the along-track XTRACK product contained much more valid data close to the coast than AVISO, not only due to the spatial downsampling in AVISO, but also to less adapted coastal processing. Here, we tackle both issues by implementing an advanced coastal along-track altimetry product. Because we find that much of the observed high-performing altimetry data have a close vicinity to the coast, our results underpin the fact that along-track data are the best choice for coastal sea level trend estimation and substantiate the results of Kleinherenbrink et al. (2018).

Accuracies of estimated VLM SAT-TG $_{\text {expressed by }}$ $\mathrm{rms}_{\triangle \mathrm{VLM}}$ are of the order of the Kleinherenbrink et al. (2018) result of $1.20 \mathrm{~mm} \mathrm{yr}^{-1}$. These results, however, cannot unequivocally be compared due to different validation settings. We extend their analysis by investigating a variety of other criteria of comparability and find that the rmssAT-TG of the differenced VLM SAT-TG $_{\text {time series provides the most robust }}$ estimates compared to correlations or the residual annual cycle. Our results also propose that increasing the radius of selection represents another improvement for VLM estimates. Practically, the approach of using absolute thresholds, which was put forward by Kleinherenbrink et al. (2018), almost halved the number of considered stations from 294 to 155 when setting an absolute correlation threshold to 0.7. Applying relative thresholds facilitates the estimation of trends at lower correlated stations, which would be rejected otherwise. This is crucial because it was frequently shown that correlations between altimetry and TGs are highly variable across the globe (WM16). Hence, we maintain the main advantage of using TGs for VLM estimation: the large global distribution compared to continuous GNSS measurements.

We highlight the fact that the SAT-TG estimates are not only limited by the broad spectrum of error sources, ranging from systematic to correction errors, such as the residual long-period tides remaining in the TG time series, which all contribute to the error budget of the estimates. Another factor is the possible nonlinearity of the VLM itself, which strongly hampers the comparability with measurements from other geodetic techniques when sampled over different time spans. Thus, addressing this issue in SAT-TG time series could represent a further crucial improvement of the application.

\section{Conclusions}

We investigate potential improvements of combining altimetry and TGs for coastal vertical land motion estimation. The innovations of our approach are twofold: (1) for the first time, we exploit a global network of high-frequency TG data (GESLA) and dedicated coastal altimetry (ALES) to determine VLM at a variety of colocated GNSS stations. Secondly, (2) we define a zone of influence to identify coherent zones of coastal SL variability, which optimizes the combination of altimetry and TGs. We rate improvements of both innovations against various SAT-TG datasets, which are comprised of along-track and gridded altimetry, as well as highfrequency (daily) and low-frequency (monthly) TG combinations.

Combining high-frequency TG with coastal altimetry data (ALES-GESLA-250 km) yields modest improvements of 
trend accuracies, compared to a monthly gridded or monthly along-track combination, when averaging SLAs in a radius of $250 \mathrm{~km}$. The high spatiotemporal resolution of the data, however, provides the foundation to identify coherent zones of sea level variability. We define a zone of influence by using relative thresholds of comparability based on rmssAT-TG, correlation, and the residual annual cycle of the altimetry and TG time series. We identify a global optimal threshold when selecting $20 \%$ of the data with the lowest rmssaT-TG. At this threshold, validation against GNSS velocity estimates (at 58 stations) yields an $\mathrm{rms}_{\triangle \mathrm{VLM}}$ of VLM $\mathrm{V}_{\mathrm{SAT}-\mathrm{TG}}$ and $\mathrm{VLM}_{\mathrm{GNSS}}$ differences of $1.28 \mathrm{~mm} \mathrm{yr}^{-1}$, with a median formal uncertainty of VLM $\mathrm{VAT}_{\text {SATG }}$ trends of $0.58 \mathrm{~mm} \mathrm{yr}^{-1}$. This refined selection method improves trend accuracy by $15 \%$ and uncertainty by $35 \%$ compared to the $250 \mathrm{~km}$ average selection. The smaller degree of improvements of trend accuracy compared to uncertainty is explained by the increasing space scales of sea level trend components with progressing timescales. We show that in many cases, capturing smallscale features of coastal sea level variability within a few tens of kilometers from the coast is vital for VLM SAT-TG $_{\text {es- }}$ timation and constantly reduces the trend uncertainty of the estimates. We thus promote using relative levels of comparability and dedicated coastal altimetry matched with highfrequency TGs to define ZOIs and increase the number of VLM estimations along the global coastline with improved uncertainty. 


\section{Appendix A: Methods}

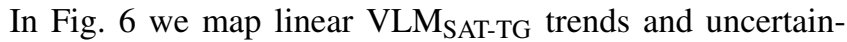
ties onto observed levels of comparability set by the correlation criterion. First, we group observed SLA time series into percentile ranges (0-20th, 20-40th, 40-60th, etc.) sorted by their correlations with the TG time series. Then, we merge the altimetry time series for each group and calculate their associated VLM $_{\text {SAT-TG }}$ trends. The resulting VLM SAT-TG $_{\text {S }}$ trends are hereinafter defined on the altimetry tracks, categorized by the aforementioned groups of comparability. To better illustrate the different zones of coherency the trends are interpolated onto a regular grid $(100 \times 100$ nodes, i.e., $6 \mathrm{~km}$ resolution) and thus smoothed as seen in Fig. 6. We use linear radial basis functions to interpolate the data.

\section{Appendix B: Significance of median biases}

To gain a better understanding of when the VLM SAT-TG $_{\text {and }}$ VLM $_{\text {GNSS }}$ difference distributions are significantly biased we create a Monte Carlo experiment to check the $\mathrm{H}_{0}$ hypothesis: "the median of the distribution is not significantly different from zero" (with alpha 0.025). Therefore, we generated a bootstrapped distribution of random medians derived from 20000 individual subsets of size 52 (the number of TGs in our dataset), which are randomly drawn from normally distributed values with an SD of $1.5 \mathrm{~mm} \mathrm{yr}^{-1}$ (according to the $\mathrm{rms}_{(\triangle \mathrm{VLM})}$ of AVISO-PSMSL-250 km) and zero mean.

Figure B1 shows that the biases of the datasets ALESPSMSL-250 km and AVISO-PSMSL-250 km exceed the 2.5 and 97.5 percentiles of the sampled distribution (average of absolute bounds: $0.512 \mathrm{~mm} \mathrm{yr}^{-1}$ ). This means that in fewer than 5 out of 100 cases, we would obtain such biases by chance, which supports the significance of these biases. We highlight the fact that this is a purely statistical analysis, which cannot account for any of the errors from corrections, adjustments and/or drifts introduced in the altimeter and GNSS.

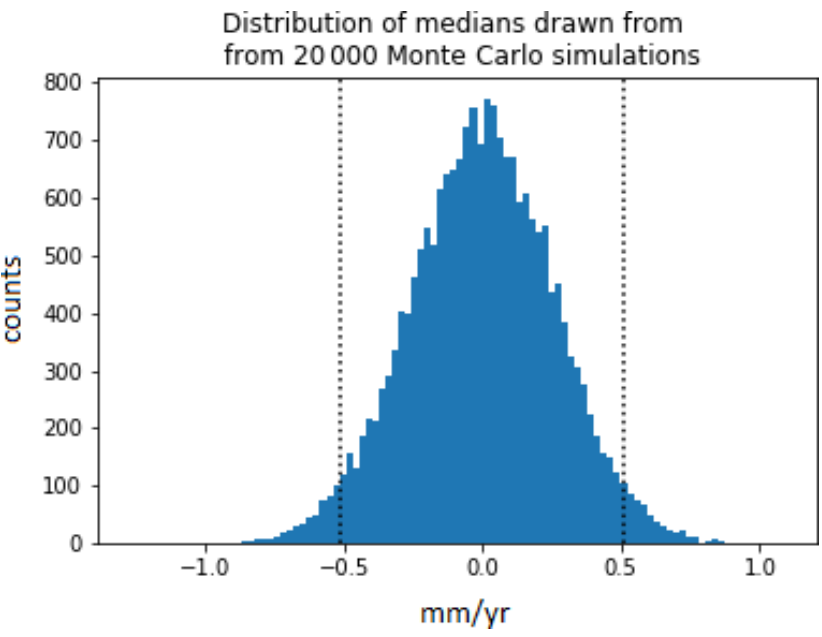

Figure B1. Histogram of median values of randomly sampled subsets. The subsets consist of 52 samples (according to the number of TGs in AVISO-PSMSL-250 km) and are randomly drawn from normally distributed values with zero mean and a standard deviation of $1.5 \mathrm{~mm} \mathrm{yr}^{-1}$ (according to the $\mathrm{rms}_{(\triangle \mathrm{VLM}}$ ) of AVISO-PSMSL$250 \mathrm{~km}$ ). Dashed lines mark the 2.5 and 97.5 percentiles of the distribution. 
Data availability. ULR6a GNSS trend estimates are obtained from the data assembly center SONEL (Systeme d'Observation du Niveau des Eaux Littorales, https://www. sonel.org/-Vertical-land-movement-estimate-.html?lang=en, last access: 10 December 2020; Santamaría-Gómez et al., 2016). GESLA tide gauge data are available at http://www.gesla.org, last access: 10 December 2020; (Woodworth et al., 2016) and PSMSL data at https://www.psmsl.org/data/obtaining/, last access: 10 December 2020; (Holgate et al., 2013). ALES along-track data are processed at DGFI-TUM (https://www.dgfi.tum.de/en/, last access: 10 December 2020) with OpenADB (https://openadb.dgfi.tum.de, last access: 10 December 2020). Averaged DT-MSLA AVISO gridded altimetry data are obtained from https://www.aviso.altimetry.fr, last access: 10 December 2020.

Author contributions. JO and MP conceptualized and designed the study. JO wrote the paper and is the author of the full software code used in this study. MP is the author of the ALES retracking algorithm and mentored the work of JO; CS and DD are responsible for the altimetry database organization and the data structure. LS provided assistance in the use of GNSS data. FS provided the basic resources making the study possible and coordinates the activities of the institute. All authors read and commented on the final paper.

Competing interests. The authors declare that they have no conflict of interest.

Acknowledgements. This work was funded by the Deutsche Forschungsgemeinschaft (DFG) (grant agreement 411072120) and the Technical University of Munich (TUM) in the framework of the Open Access Publishing Program. We thank the data providers GESLA, PSMSL, SONEL and AVISO for the opportunity to use their products. We thank Sergiy Rudenko, Ashwita Chouksey and Michael Hart-Davis for their help and comments. We are very grateful for the comments of the reviewers, Alvaro Santamaría Gómez and Christopher Watson, which strongly improved the paper.

Financial support. This research has been supported by the Deutsche Forschungsgemeinschaft (DFG) (grant no. 411072120).

This work was supported by the German Research Foundation (DFG) and the Technical University of Munich (TUM) in the framework of the Open Access Publishing Program.

Review statement. This paper was edited by Joanne Williams and reviewed by Alvaro Santamaría-Gómez and Christopher Watson.

\section{References}

Ablain, M., Cazenave, A., Valladeau, G., and Guinehut, S.: A new assessment of the error budget of global mean sea level rate estimated by satellite altimetry over 1993-2008, Ocean Sci., 5, 193201, https://doi.org/10.5194/os-5-193-2009, 2009.

Agnew, D. C.: The time-domain behavior of powerlaw noises, Geophys. Res. Lett., 19, 333-336, https://doi.org/10.1029/91GL02832, 1992.

Andersen, O. B., Nielsen, K., Knudsen, P., Hughes, C. W., FenoglioMarc, L., Gravelle, M., Kern, M., and Polo, S. P.: Improving the Coastal Mean Dynamic Topography by Geodetic Combination of Tide Gauge and Satellite Altimetry, Mar. Geod., 41, 517-545, https://doi.org/10.1080/01490419.2018.1530320, 2018.

Ballu, V., Gravelle, M., Wöppelmann, G., de Viron, O., Rebischung, P., Becker, M., and Sakic, P.: Vertical land motion in the Southwest and Central Pacific from available GNSS solutions and implications for relative sea levels, Geophys. J. Int., 218, 15371551, https://doi.org/10.1093/gji/ggz247, 2019.

Bloßfeld, M., Angermann, D., and Seitz, M.: DGFI-TUM Analysis and Scale Investigations of the Latest Terrestrial Reference Frame Realizations, in: International Symposium on Advancing Geodesy in a Changing World, edited by: Freymueller, J. T. and Sánchez, L., Springer International Publishing, Cham, 3-9, 2019.

Bos, M. S., Fernandes, R. M. S., Williams, S. D. P., and Bastos, L.: Fast Error Analysis of Continuous GNSS Observations with Missing Data.J. Geod., 87, 351-360, https://doi.org/10.1007/s00190-012-0605-0, 2013.

Bosch, W. and Savcenko, R.: Satellite altimetry: Multi-mission cross calibration, in: Dynamic Planet, International Association of Geodesy Symposia, edited by: Tregoning P. and Rizos C., Vol. 130, Springer, Berlin, Heidelberg, https://doi.org/10.1007/978-3-540-49350-1_8, 2007.

Bosch, W., Dettmering, D., and Schwatke, C.: Multi-Mission CrossCalibration of Satellite Altimeters: Constructing a Long-Term Data Record for Global and Regional Sea Level Change Studies, Remote Sens., 6, 2255-2281, 2014.

Bouin, M. N. and Wöppelmann, G.: Land motion estimates from GPS at tide gauges: a geophysical evaluation, Geophys. J. Int., 180, 193-209, https://doi.org/10.1111/j.1365246X.2009.04411.x, 2010.

Brooks, B. A., Merrifield, M. A., Foster, J., Werner, C. L., Gomez, F., Bevis, M., and Gill, S.: Space geodetic determination of spatial variability in relative sea level change, Los Angeles basin, Geophys. Res. Lett., 34, L01611, https://doi.org/10.1029/2006GL028171, 2007.

Calafat, F. M., Wahl, T., Lindsten, F., Williams, J., and FrajkaWilliams, E.: Coherent modulation of the sea-level annual cycle in the United States by Atlantic Rossby waves, Nat. Commun., 9, 2571, https://doi.org/10.1038/s41467-018-04898-y, 2018.

Carrere, L., Faugère, Y., and Ablain, M.: Major improvement of altimetry sea level estimations using pressure-derived corrections based on ERA-Interim atmospheric reanalysis, Ocean Sci., 12, 825-842, https://doi.org/10.5194/os-12-825-2016, 2016.

Carrère, L. and Lyard, F.: Modeling the barotropic response of the global ocean to atmospheric wind and pressure forcing comparisons with observations, Geophys. Res. Lett., 30, 1275, https://doi.org/10.1029/2002GL016473, 2003.

Carrère, L., Lyard, F., Cancet, M., and Guillot, A.: FES 2014, a new tidal model on the global ocean with enhanced accuracy in shal- 
low seas and in the Arctic region, in: EGU General Assembly Conference Abstracts, EGU General Assembly Conference Abstracts, p. 5481, 2015.

Carson, M., Köhl, A., Stammer, D., Slangen, A., Katsman, C., Wal, R., Church, J., and White, N.: Coastal Sea Level Changes, Observed and Projected during the 20th and 21st Century, Climatic Change, 134, 269-281, https://doi.org/10.1007/s10584015-1520-1, 2016.

Cazenave, A., Dominh, K., Ponchaut, F., Soudarin, L., Cretaux, J. F., and Le Provost, C.: Sea level changes from Topex-Poseidon altimetry and tide gauges, and vertical crustal motions from DORIS, Geophys. Res. Lett., 26, 2077-2080, https://doi.org/10.1029/1999GL900472, 1999.

Cazenave, A., Palanisamy, H., and Ablain, M.: Contemporary sea level changes from satellite altimetry: What have we learned? What are the new challenges?, Adv. Space Res., 62, 1639-1653, https://doi.org/10.1016/j.asr.2018.07.017, 2018.

Church, J. and White, N.: Sea-Level Rise from the Late 19th to the Early 21st Century, Surv. Geophys., 32, 585-602, https://doi.org/10.1007/s10712-011-9119-1, 2011.

Church, J. A., Clark, P., Cazenave, A., Gregory, J., Jevrejeva, S., Levermann, A., Merrifield, M., Milne, G., Nerem, R., Nunn, P., Payne, A., Pfeffer, W., Stammer, D., and Unnikrishnan, A.: 2013: Sea level change, in: Climate Change 2013: The Physical Science Basis. Contribution of Working Group I to the Fifth Assessment Report of the Intergovernmental Panel on Climate Change, edited by: Stocker, T. F., Qin, D., Plattner, G.K., Tignor, M., Allen, S. K., Boschung, J., Nauels, A., Xia, Y., Bex, V., and Midgley, P. M., Cambridge University Press, Cambridge, United Kingdom and New York, NY, USA, 1137-1216, https://doi.org/10.1017/CB09781107415315.026, 2013.

Cipollini, P., Calafat, F. M., Jevrejeva, S., Melet, A., and Prandi, P.: Monitoring Sea Level in the Coastal Zone with Satellite Altimetry and Tide Gauges, Surv. Geophys., 38, 33-57, https://doi.org/10.1007/s10712-016-9392-0, 2017.

Cleveland, W. S. and Devlin, S. J.: Locally Weighted Regression: An Approach to Regression Analysis by Local Fitting, J. Am. Stat. Assoc., 83, 596-610, available at: http://www.jstor.org/ stable/2289282 (last access: 10 December 2020), 1988.

Collilieux, X. and Woppelmann, G.: Global sea-level rise and its relation to the terrestrial reference frame, J. Geodesy, 85, 9-22, https://doi.org/10.1007/s00190-010-0412-4, 2009.

Couhert, A., Cerri, L., Legeais, J.-F., Michaël, A., Zelensky, N., Haines, B., Lemoine, F., Bertiger, W., Desai, S., and Otten, M.: Towards the $1 \mathrm{~mm} / \mathrm{y}$ stability of the radial orbit error at regional scales, Adv. Space Res., 55, https://doi.org/10.1016/j.asr.2014.06.041, 2015.

Dangendorf, S., Marcos, M., Wöppelmann, G., Conrad, C. P., Frederikse, T., and Riva, R.: Reassessment of 20th century global mean sea level rise, P. Natl. Acad. Sci. USA, 114, 5946-5951, https://doi.org/10.1073/pnas.1616007114, 2017.

Dettmering D., Schwatke C. (2019) Multi-Mission CrossCalibration of Satellite Altimeters. In: Mertikas S., Pail R. (eds) Fiducial Reference Measurements for Altimetry. International Association of Geodesy Symposia, vol 150. Springer, Cham, https://doi.org/10.1007/1345_2019_58, 2019.

Ducet, N., Le Traon, P. Y., and Reverdin, G.: Global highresolution mapping of ocean circulation from TOPEX/Poseidon and ERS-1 and -2, J. Geophys. Res.-Oceans, 105, 19477-19498, https://doi.org/10.1029/2000JC900063, 2000.

Fenoglio, L., Schöne, T., Illigner, J., Becker, M., Manurung, P., and Khafid: Sea Level Change and Vertical Motion from Satellite Altimetry, Tide Gauges and GPS in the Indonesian Region, Mar. Geod., 35, https://doi.org/10.1080/01490419.2012.718682, 2012.

Fernandes, M. J., Lázaro, C., Ablain, M., and Pires, N.: Remote Sensing of Environment Improved wet path delays for all ESA and reference altimetric missions, Remote Sens. Environ., 169, 50-74, https://doi.org/10.1016/j.rse.2015.07.023, 2015.

Frederikse, T., Landerer, F. W., and Caron, L.: The imprints of contemporary mass redistribution on local sea level and vertical land motion observations, Solid Earth, 10, 1971-1987, https://doi.org/10.5194/se-10-1971-2019, 2019.

Hamlington, B. D., Thompson, P., Hammond, W. C., Blewitt, G., and Ray, R. D.: Assessing the impact of vertical land motion on twentieth century global mean sea level estimates, J. Geophys. Res.-Oceans, 121, 4980-4993 https://doi.org/10.1002/2016JC011747, 2016.

Hawkins, R., Husson, L., Choblet, G., Bodin, T., and Pfeffer, J.: Virtual Tide Gauges for Predicting Relative Sea Level Rise, J. Geophys. Res.-Sol. Ea., 124, 13367-13391, https://doi.org/10.1029/2019JB017943, 2019.

Hay, C. C., Morrow, E., Kopp, R. E., and Mitrovica, J. X.: Probabilistic reanalysis of twentieth-century sea-level rise, Nature, 517, 481-484, https://doi.org/10.1038/nature14093, 1990.

Holgate, S. J., Matthews, A., Woodworth, P. L., Rickards, L. J., Tamisiea, M. E., Bradshaw, E., Foden, P. R., Gordon, K. M., Jevrejeva, S., and Pugh, J.: New Data Systems and Products at the Permanent Service for Mean Sea Level, J. Coastal Res., 493 504, https://doi.org/10.2112/JCOASTRES-D-12-00175.1, 2013.

Hughes, C. and Meredith, M.: Coherent sea-level fluctuations along the global continental slope, Philos. T. R. Soc. A, 364, 885-901, https://doi.org/10.1098/rsta.2006.1744, 2006.

Hughes, C. W., Fukumori, I., Griffies, S. M., and Huthnance, J. M.: Sea Level and the Role of Coastal Trapped Waves in Mediating the Influence of the Open Ocean on the Coast, Surv. Geophys., 40, 1467-1492, https://doi.org/10.1007/s10712-01909535-x, 2019.

Idžanović, M., Gerlach, C., Breili, K., and Andersen, O.: An Attempt to Observe Vertical Land Motion along the Norwegian Coast by CryoSat-2 and Tide Gauges, Remote Sens.-Basel, 11, 744, https://doi.org/10.3390/rs11070744, 2019.

Jevrejeva, S., Moore, J. C., Grinsted, A., Matthews, A. P., and Spada, G.: Trends and acceleration in global and regional sea levels since 1807, Global Planet. Change, 113, 11-22, https://doi.org/10.1016/j.gloplacha.2013.12.004, 2014.

King, M. A., Keshin, M., Whitehouse, P. L., Thomas, I. D., Milne, G., and Riva, R. E. M.: Regional biases in absolute sealevel estimates from tide gauge data due to residual unmodeled vertical land movement, Geophys. Res. Lett., 39, L14604, https://doi.org/10.1029/2012GL052348, 2012.

Kleinherenbrink, M., Riva, R., and Frederikse, T.: A comparison of methods to estimate vertical land motion trends from GNSS and altimetry at tide gauge stations, Ocean Sci., 14, 187-204, https://doi.org/10.5194/os-14-187-2018, 2018.

Kolker, A. S., Allison, M. A., and Hameed, S.: An evaluation of subsidence rates and sea-level variability in the 
northern Gulf of Mexico, Geophys. Res. Lett., 38, L21404, https://doi.org/10.1029/2011GL049458, 2011.

Kuo, C. Y., Shum, C. K., Braun, A., and Mitrovica, J. X.: Vertical crustal motion determined by satellite altimetry and tide gauge data in Fennoscandia, Geophys. Res. Lett., 31, L01608, https://doi.org/10.1029/2003GL019106, 2004.

Kurapov, A., Erofeeva, S., and Myers, E.: Coastal sea level variability in the US West Coast Ocean Forecast System (WCOFS), Ocean Dynam., 67, 23-36, https://doi.org/10.1007/s10236-0161013-4, 2016

Landskron, D. and Böhm, J.: Refined discrete and empirical horizontal gradients in VLBI analysis, J. Geodesy, 92, 1387-1399, https://doi.org/10.1007/s00190-018-1127-1, 2018.

Mazzotti, S., Jones, C., and Thomson, R. E.: Relative and absolute sea level rise in western Canada and northwestern United States from a combined tide gauge-GPS analysis, J. Geophys. Res.Oceans, 113, C11019, https://doi.org/10.1029/2008JC004835, 2008.

Moritz, H.: Geodetic Reference System 1980, J. Geodesy, 74, 128 133, https://doi.org/10.1007/s001900050278, 2000.

Nerem, R. S. and Mitchum, G. T.: Estimates of vertical crustal motion derived from differences of TOPEX/POSEIDON and tide gauge sea level measurements, Geophys. Res. Lett., 29, 1934, https://doi.org/10.1029/2002gl015037, 2003.

Passaro, M., Cipollini, P., Vignudelli, S., Quartly, G. D., and Snaith, H. M.: ALES: A multi-mission adaptive subwaveform retracker for coastal and open ocean altimetry, Remote Sens. Environ., 145, 173-189, https://doi.org/10.1016/j.rse.2014.02.008, 2014.

Passaro, M., Cipollini, P., and Benveniste, J.: Annual sea level variability of the coastal ocean: The Baltic Sea-North Sea transition zone, J. Geophys. Res.-Oceans, 120, 3061-3078, https://doi.org/10.1002/2014JC010510, 2015.

Passaro, M., Müller, F. L., and Dettmering, D.: Lead detection using Cryosat-2 delay-doppler processing and Sentinel-1 SAR images, Adv. Space Res., 62, 1610-1625, https://doi.org/10.1016/j.asr.2017.07.011, 2018.

Peltier, W.: GLOBAL GLACIAL ISOSTASY AND THE SURFACE OF THE ICE-AGE EARTH: The ICE-5G (VM2) Model and GRACE, Annu. Rev. Earth Pl. Sc., 32, 111-149, https://doi.org/10.1146/annurev.earth.32.082503.144359, 2004.

Petit, G. and Luzum, B.: IERS Conventions, Verlag des Bundesamts für Kartographie und Geodäsie, Frankfurt, Germany, 2010.

Pfeffer, J. and Allemand, P.: The key role of vertical land motions in coastal sea level variations: A global synthesis of multisatellite altimetry, tide gauge data and GPS measurements, Earth Planet. Sc. Lett., 439, 39-47, https://doi.org/10.1016/j.epsl.2016.01.027, 2016

Pfeffer, J., Spada, G., Mémin, A., Boy, J.-P., and Allemand, P.: Decoding the origins of vertical land motions observed today at coasts, Geophys. J. Int., 210, 148-165, https://doi.org/10.1093/gji/ggx142, 2017.

Piccioni, G., Dettmering, D., Passaro, M., Schwatke, C., Bosch, W., and Seitz, F.: Coastal Improvements for Tide Models: The Impact of ALES Retracker, Remote Sens.-Basel, 10, 700, https://doi.org/10.3390/rs10050700, 2018.

Piccioni, G., Dettmering, D., Schwatke, C., Passaro, M., and Seitz, F.: Design and regional assessment of an empirical tidal model based on FES2014 and coastal altimetry, Adv. Space Res., https://doi.org/10.1016/j.asr.2019.08.030, 2019.
Poitevin, C., Wöppelmann, G., Raucoules, D., Cozannet, G. L., Marcos, M., and Testut, L.: Vertical land motion and relative sea level changes along the coastline of Brest (France) from combined space-borne geodetic methods, Remote Sens. Environ., 222, 275-285, https://doi.org/10.1016/j.rse.2018.12.035, 2019.

Ponte, R. M.: Low-Frequency Sea Level Variability and the Inverted Barometer Effect, J. Atmos. Ocean. Tech., 23, 619-629, https://doi.org/10.1175/JTECH1864.1, 2006.

Pugh, D. and Woodworth, P.: Sea-Level Science: Understanding Tides, Surges, Tsunamis and Mean SeaLevel Changes, Cambridge University Press, Cambridge, https://doi.org/10.1017/CBO9781139235778, 2014.

Riva, R. E. M., Frederikse, T., King, M. A., Marzeion, B., and van den Broeke, M. R.: Brief communication: The global signature of post-1900 land ice wastage on vertical land motion, The Cryosphere, 11, 1327-1332, https://doi.org/10.5194/tc-11-13272017, 2017.

Sanli, D. and Blewitt, G.: Geocentric sea level trend using GPS and >100-year tide gauge record on a postglacial rebound nodal line, J. Geophys. Res., 106, 713-720, https://doi.org/10.1029/2000JB900348, 2001.

Santamaría-Gómez, A., Bouin, M.-N., Collilieux, X., and Wöppelmann, G.: Correlated errors in GPS position time series: Implications for velocity estimates, J. Geophys. Res.-Sol. Ea., 116, B01405, https://doi.org/10.1029/2010JB007701, 2011.

Santamaría-Gómez, A., Gravelle, M., Collilieux, X., Guichard, M., Míguez, B. M., Tiphaneau, P., and Wöppelmann, G.: Mitigating the effects of vertical land motion in tide gauge records using a state-of-the-art GPS velocity field, Global Planet. Change, 9899, 6-17, https://doi.org/10.1016/j.gloplacha.2012.07.007, 2012

Santamaría-Gómez, A., Gravelle, M., and Wöppelmann, G.: Long-term vertical land motion from double-differenced tide gauge and satellite altimetry data, J. Geodesy, 88, 207-222, https://doi.org/10.1007/s00190-013-0677-5, 2014.

Santamaría-Gómez, A., Gravelle, M., and Wöppelmann, G.: GPS Solution ULR6, SONEL Data Center, https://doi.org/10.26166/sonel_ulr6a, 2016.

Santamaría-Gómez, A., Gravelle, M., Dangendorf, S., Marcos, M., Spada, G., and Wöppelmann, G.: Uncertainty of the 20th century sea-level rise due to vertical land motion errors, Earth Planet. Sc. Lett., 473, 24-32, https://doi.org/10.1016/j.epsl.2017.05.038, 2017.

Saraceno, M., Strub, P. T., and Kosro, P. M.: Estimates of sea surface height and near-surface alongshore coastal currents from combinations of altimeters and tide gauges, J. Geophys. Res.-Oceans, 113, C11013, https://doi.org/10.1029/2008JC004756, 2008.

Sánchez, L. and Bosch, W.: The role of the TIGA project in the unification of classical height systems, in: Geodetic Reference Frames, IAG Symposia 134, edited by: Drewes H., Springer, https://doi.org/10.1007/978-3-642-00860-3_44, 285-290, 2009.

Scharroo, R. and Smith, W. H. F.: A global positioning system-based climatology for the total electron content in the ionosphere, J. Geophys. Res.-Space, 115, https://doi.org/10.1029/2009JA014719, 2010.

Scharroo, R., Leuliette, E., Lillibridge, J., Byrne, D., Naeije, M., and Mitchum, G.: RADS: Consistent multi-mission products, in: Proceedings of Symposium on 20 Years of Progress in Radar Altimetry, 24-29 September 2012, Venice, 20, 59-60, 2012. 
Slangen, A. B. A., Carson, M., Katsman, C. A., van de Wal, R. S. W., Köhl, A., Vermeersen, L. L. A., and Stammer, D.: Projecting twenty-first century regional sea-level changes, Climatic Change, 124, 317-332, https://doi.org/10.1007/s10584014-1080-9, 2014.

Snay, R., Cline, M., Dillinger, W., Foote, R., Hilla, S., Kass, W., Ray, J., Rohde, J., Sella, G., and Soler, T.: Using global positioning system-derived crustal velocities to estimate rates of absolute sea level change from North American tide gauge records, J. Geophys. Res.-Sol. Ea., 112, https://doi.org/10.1029/2006JB004606, 2007.

Stammer, D. and Böning, C. W.: Mesoscale Variability in the Atlantic Ocean from Geosat Altimetry and WOCE High-Resolution Numerical Modeling, J. Phys. Oceanogr., 22, 732-752, https://doi.org/10.1175/15200485(1992)022<0732:MVITAO>2.0.CO;2, 1992.

Stammer, D., Cazenave, A., Ponte, R. M., and Tamisiea, M. E.: Causes for Contemporary Regional Sea Level Changes, Annu. Rev. Mar. Sci., 5, 21-46, https://doi.org/10.1146/annurevmarine-121211-172406, pMID: 22809188, 2013.

Veit, E. and Conrad, C. P.: The impact of groundwater depletion on spatial variations in sea level change during the past century, Geophys. Res. Lett., 43, 3351-3359, https://doi.org/10.1002/2016GL068118, 2016.

Wada, Y., van Beek, L. P. H., Sperna Weiland, F. C., Chao, B. F., Wu, Y.-H., and Bierkens, M. F. P.: Past and future contribution of global groundwater depletion to sea-level rise, Geophys. Res. Lett., 39, L09402, https://doi.org/10.1029/2012GL051230, 2012.
Watson, C., White, N., Church, J., King, M., Burgette, R., and Legresy, B.: Unabated global mean sea-level rise over the satellite altimter era, Nat. Clim. Change, 5, https://doi.org/10.1038/nclimate2635, 2015.

Woodworth, P. L., Hunter, J. R., Marcos, M., Caldwell, P. Menéndez, M., and Haigh, I.: Towards a global higherfrequency sea level dataset, Geosci. Data J., 3, 50-59, https://doi.org/10.1002/gdj3.42, 2016.

Woodworth, P. L., Melet, A., Marcos, M., Ray, R. D., Wöppelmann, G., Sasaki, Y. N., Cirano, M., Hibbert, A., Huthnance, J. M., Monserrat, S., and Merrifield, M. A.: Forcing factors affecting sea level changes at the coast, Surv. Geophys., 40, 1351-1397, available at: http://nora.nerc.ac.uk/id/eprint/523283/ (last access: 10 December 2020), 2019.

Wöppelmann, G. and Marcos, M.: Vertical land motion as a key to understanding sea level change and variability, Rev. Geophys., 54, 64-92, https://doi.org/10.1002/2015RG000502, 2016.

Wöppelmann, G., Martin Miguez, B., Bouin, M.-N., and Altamimi, Z.: Geocentric sea-level trend estimates from GPS analyses at relevant tide gauges world-wide, Global Planet. Change, 57, 396-406, https://doi.org/10.1016/j.gloplacha.2007.02.002, 2007.

Wöppelmann, G., Gravelle, M., Guichard, M., and Prouteau, E.: Fourth Progress Report on the GNSS at Tide Gauge Activities: SONEL Data Holdings \& Tools to access the data, presented at the XVIth GLOSS group of experts meeting, hosted by the Korean Hydrographic and Oceanographic Agency, Busan (Republic of Korea), 11-13 April 2019, available at: https://www.sonel.org/ IMG/pdf/ge16_gnssattg_activities_sonel_report_v2.pdf, 2019. 